\title{
Presynaptic Modulation of Spinal Nociceptive Transmission by Glial Cell Line-Derived Neurotrophic Factor (GDNF)
}

\author{
Chiara Salio, ${ }^{1}{ }^{-}$Francesco Ferrini, ${ }^{1 \star}$ Sangu Muthuraju, ${ }^{1 \star}$ and ${ }^{\circ}$ Adalberto Merighi ${ }^{1,2}$ \\ ${ }^{1}$ University of Turin, Department of Veterinary Sciences and ${ }^{2}$ National Institute of Neuroscience, 10095 Grugliasco, Italy
}

The role of glial cell line-derived neurotrophic factor (GDNF) in nociceptive pathways is still controversial, as both pronociceptive and antinociceptive actions have been reported. To elucidate this role in the mouse, we performed combined structural and functional studies in vivo and in acute spinal cord slices where $\mathrm{C}$-fiber activation was mimicked by capsaicin challenge.

Nociceptors and their terminals in superficial dorsal horn (SDH; laminae I-II) constitute two separate subpopulations: the peptidergic CGRP/somatostatin + cells expressing GDNF and the nonpeptidergic IB4+ neurons expressing the GFR $\alpha 1$-RET GDNF receptor complex. Ultrastructurally the dorsal part of inner lamina $\mathrm{II}\left(\mathrm{LII}_{\mathrm{i}} \mathrm{d}\right)$ harbors a mix of glomeruli that either display GDNF/somatostatin (GIb)-IR or GFR $\alpha 1 /$ IB 4 labeling (GIa). LII $_{\mathrm{i}} \mathrm{d}$ thus represents the preferential site for ligand-receptor interactions.

Functionally, endogenous GDNF released from peptidergic CGRP/somatostatin + nociceptors upon capsaicin stimulation exert a tonic inhibitory control on the glutamate excitatory drive of SDH neurons as measured after ERK1/2 phosphorylation assay. Real-time $\mathrm{Ca}^{2+}$ imaging and patch-clamp experiments with bath-applied GDNF (100 nM) confirm the presynaptic inhibition of SDH neurons after stimulation of capsaicin-sensitive, nociceptive primary afferent fibers. Accordingly, the reduction of the capsaicin-evoked $\left[\mathrm{Ca}^{2+}\right]_{\mathrm{i}}$ rise and of the frequency of mEPSCs in SDH neurons is specifically abolished after enzymatic ablation of GFR $\alpha 1$. Therefore, GDNF released from peptidergic CGRP/somatostatin + nociceptors acutely depresses neuronal transmission in SDH signaling to nonpeptidergic IB4+ nociceptors at glomeruli in $\mathrm{LII}_{\mathrm{i}} \mathrm{d}$. These observations are of potential pharmacological interest as they highlight a novel modality of cross talk between nociceptors that may be relevant for discrimination of pain modalities.

Key words: GDNF; glomeruli; lamina II; spinal cord; transmitters; ultrastructure

\section{Introduction}

Glial cell line-derived neurotrophic factor (GDNF) promotes the survival of peripheral and central neurons. Not only is it essential for the maturation and maintenance of subsets of sensory neurons, but also for modulating their functional properties (Molliver et al., 1997; Bennett et al., 1998). Specifically, GDNF supports the survival of dorsal root ganglion (DRG) neurons in vitro and in vivo (Matheson et al., 1997; Molliver et al., 1997; Bennett et al., 1998), and their regeneration during adulthood (Ramer et al., 2000). Interestingly, the cell membrane of DRG neurons supported by GDNF binds the isolectin B4 (IB4) produced by Griffonia simplicifolia (Molliver et al., 1997), which labels a subpopulation of nociceptors devoid of neuropeptides

Received Feb. 27, 2014; revised July 30, 2014; accepted Aug. 1, 2014.

Author contributions: C.S., F.F., and A.M. designed research; C.S. and S.M. performed research; F.F., S.M., and A.M. analyzed data; C.S., F.F., and A.M. wrote the paper.

This work was supported by grants from the Italian MiUR (Fondi PRIN 2008) and Compagnia di San Paolo (Torino, Italy) to A.M. and UniTO-Compagnia di San Paolo-EU Accelerating Grants (PANTAPAIN) to C.S., S.M. was the recipient of a postdoctoral fellowship under an India-Italy bilateral agreement sponsored by the University of Turin and Compagnia di San Paolo. We thank Dr. Matthew Bradman for critically reading of this manuscript.

*F.F. and S.M. contributed equally to this work.

The authors declare no competing financial interests.

Correspondence should be addressed to Adalberto Merighi, University of Turin, Department of Veterinary Sciences, Largo Paolo Braccini 2, 10095 Grugliasco (T0), Italy. E-mail: adalberto.merighi@unito.it.

S. Muthuraju's present address: Laboratory of Neuropsychopharmacology, FFCLRP, Universidade de São Paulo, Campus USP, Ribeirão Preto, SP 14049-901, Brazil.

DOI:10.1523/JNEUROSCI.0808-14.2014

Copyright $\odot 2014$ the authors $\quad 0270-6474 / 14 / 3413819-15 \$ 15.00 / 0$
(Bennett et al., 1998, 2000). Consistent with this observation, nonpeptidergic IB4+ nociceptors express the receptor complex that transduces the effects of GDNF: the GDNF-family receptor $\alpha 1$ (GFR $\alpha 1$; Treanor et al., 1996) and the transmembrane tyrosine kinase receptor RET (Durbec et al., 1996).

As for the most widely investigated growth factors of the neurotrophin family (Park and Poo, 2013), evidence is accumulating that GDNF is actively secreted (Lonka-Nevalaita et al., 2010), and can thus act as an extracellular messenger with biological effects over wide spatial and temporal scales. In keeping with this possibility, GDNF plays a role in the somatosensory system by modulating somatostatin (SST) expression (Adler, 1998) and release from DRGs (Charbel Issa et al., 2001; Malcangio et al., 2002; Malcangio, 2003). Also, GDNF enhances the capsaicin-stimulated release of calcitonin gene-related peptide (CGRP) from cultured adult DRG neurons (Schmutzler et al., 2009). GDNF is expressed in smallto medium-sized DRG neurons and in fibers of laminae I-II of the $\mathrm{DH}$ (herein referred to as superficial dorsal horn or SDH; Holstege et al., 1998; Ohta et al., 2001), and has been suggested to undergo anterograde transport along primary afferent fibers (PAFs) projecting to periphery and spinal cord (Ohta et al., 2001; Rind and von Bartheld, 2002).

Therefore, a role of GDNF as a modulator of the nociceptive information transfer between first- and second-order neurons in SDH emerged (for review, see Malcangio, 2003), but still remained controversial (Sah et al., 2005; for review, see Bartolini et 
al., 2011), as both pronociceptive and antinociceptive effects have been reported depending on the peripheral territory innervated (skin, muscle), type of pain (inflammatory vs neuropathic), and stimulus (mechanical, thermal, and noxious).

To shed more light on GDNF signaling in SDH, we used a combination of structural and functional techniques in intact postnatal and juvenile mice, as well as in acute spinal cord slices challenged with capsaicin to mimic inflammation in vitro (Vergnano et al., 2008).

Our findings demonstrate not only that GDNF acutely reduces nociceptive transmission at synapses between firstand second-order neurons in SDH, but also unravels a novel yet unrecognized path of communication between peptidergic and nonpeptidergic PAFs, which is likely to have interesting implications in our comprehension of the transfer of nociceptive information between peripheral and central neurons.

\section{Materials and Methods}

Animals. All experiments were performed according to $\mathrm{EU}$ and national regulations on animal welfare and have been authorized by the Italian Ministry of Health (600.8/82.20/ AG1826). All procedures were performed following deep pentobarbital anesthesia $(3 \mathrm{mg} / 100 \mathrm{~g})$.

Sixty postnatal (P8-P12) CD1 male mice were used for $\mathrm{Ca}^{2+}$ imaging and patch-clamp experiments, and GDNF ELISA. Thirty-six postnatal and juvenile (P21-P23) CD1 male mice were used for immunocytochemical studies. These included 10 P8-P12 and 14 P21-P23 mice for light microscopy (LM) and 12 mice for electron microscopy (EM) studies (four P21-P23 mice for Lowicryl embedding and four P8-P12 mice and four P21-P23 mice for Araldite embedding).

The rationale behind the use of postnatal and juvenile animals is related to the well known pattern of postnatal maturation of spinal cord circuitry (Fitzgerald, 2005). Although in P8-P12 mice spinal cord networks still undergo maturation, we have previously shown that there are no differences in the electrophysiological response to capsaicin recorded in slices from postnatal or juvenile mice (Ferrini et al., 2010). Therefore, taking into consideration the difficulties in bulk loading of the $\mathrm{Ca}^{2+}$ indicator at P21-P23, we have decided to perform all functional experiments in postnatal animals as in previous $\mathrm{Ca}^{2+}$ imaging experiments in rats (Merighi et al., 2008). At the same time, for better data consistency, immunocytochemical studies were for the most performed at both ages.

Primary antibodies and controls. Primary antibodies were rabbit anti-GDNF (1:100 LM, 1:20 EM; Santa Cruz Biotechnology catalog sc-328 RRID:AB_2247684), rabbit anti-SST 28 (1: 2000 LM, 1:100 EM; Merighi et al., 1989), chicken anti-human BDNF (1:500 LM, 1:20 EM; Promega catalog G1641 RRID:AB_430850; Salio et
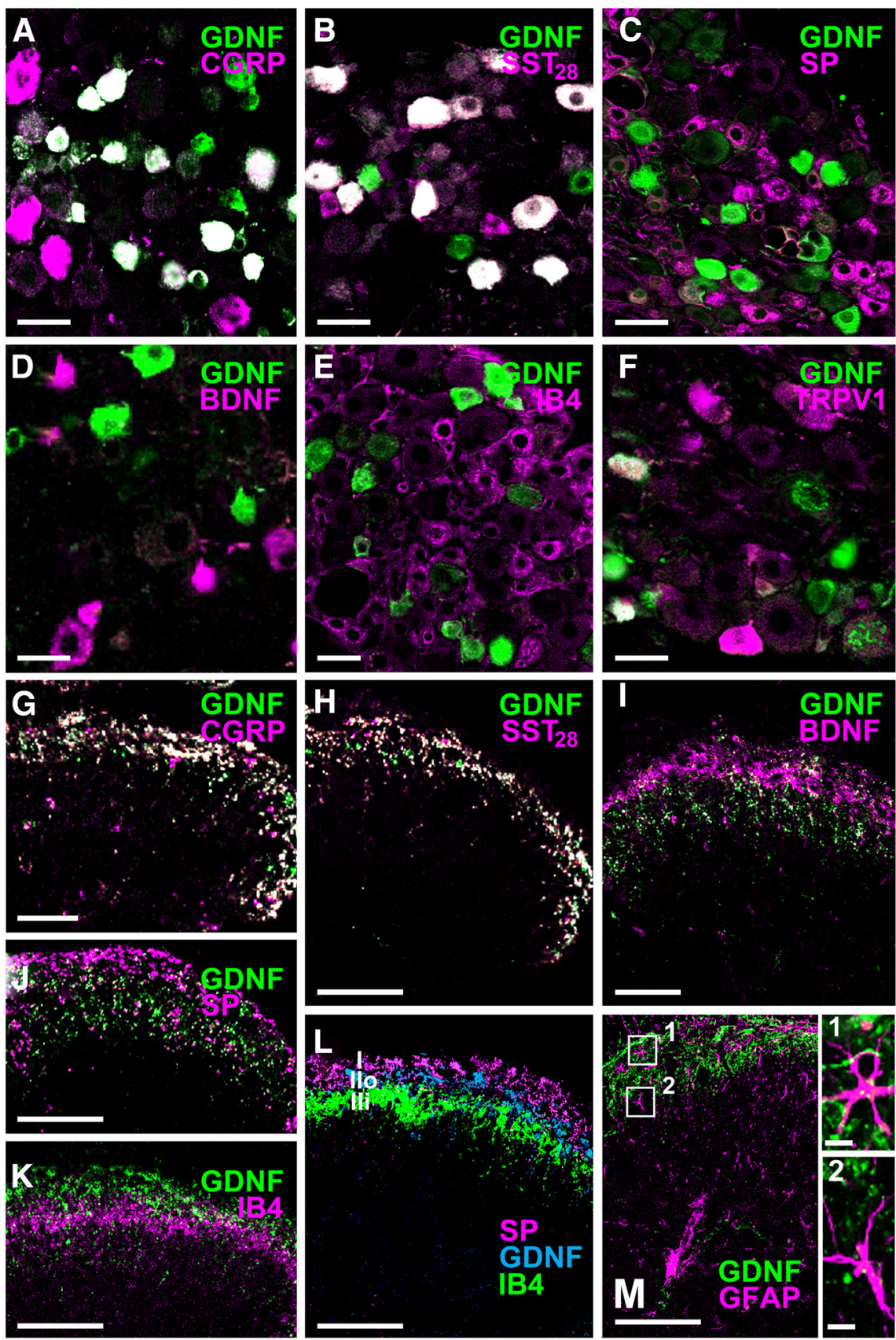

Figure 1. Distribution of GDNF in DRG and DH and colocalization with markers of $n$ PAFs and glia. $A, G D N F$ and CGRP coexpression (white) in small- to medium-sized neurons. $\boldsymbol{B}$, Small- to medium-sized neurons double stained for GDNF and $\mathrm{SST}_{28}$ (white). $\boldsymbol{C}$, GDNF (green) and SP (magenta) are distributed in two different populations of small- to medium-sized neurons. D, GDNF-IR neurons (green) do not express BDNF (magenta). $\boldsymbol{E}$, GDNF (green) and IB4 (magenta) are distributed in two different populations of neurons. $\boldsymbol{F}$, GDNF + TRVP1-IR neurons (white) of small to medium size. G, GDNF and CGRP coexpression (white) in peptidergic nPAFs of SDH. $\boldsymbol{H}$, GDNF and SST 28 coexpression (white) in peptidergic nPAFs of SDH. I, GDNF (green) and BDNF (magenta) are distributed in two different subpopulations of peptidergic nPAFs of SDH.J, GDNF (green) and SP (magenta) IRs are localized in two different populations of fibers in SDH. $\boldsymbol{K}$, GDNF (green) and IB4 (magenta) are localized in two different populations of fibers in SDH. $\boldsymbol{L}$, Triple immunolabeling demonstrates that GDNF (turquoise) is principally expressed in fibers of lamina II, in a band between the more dorsal band of SP-IR (magenta) and the more ventral band of IB4 + processes (green). The three markers are thus expressed by different populations of nPAFs. $M$, GDNF (green) is localized in nPAFs of lamina II while GFAP (magenta) is expressed in astrocytes throughout the spinal cord. Some GDNF-IR fibers are close to or in contact with GFAP + astrocytes (inserts 1 and 2). Scale bars: $\boldsymbol{A}-\boldsymbol{E}, 50 \mu \mathrm{m} ; \boldsymbol{F}-\boldsymbol{L}, 250 \mu \mathrm{m}$; inserts, $15 \mu \mathrm{m}$. al., 2007), rabbit anti-CGRP (1:1000 LM, 1:100 EM; Merighi et al., 1991), rat anti-substance P (SP; 1:500 LM, 1:20 EM; BD Biosciences catalog 556312 RRID:AB_396357), goat anti-GFR $\alpha 1$ (1:300; Neuromics catalog GT15004 RRID:AB_2307379), goat anti-RET (1:100; R\&D Systems 


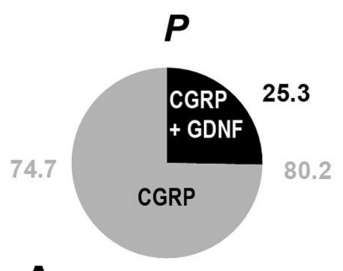

A

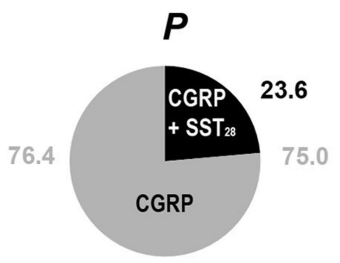

C

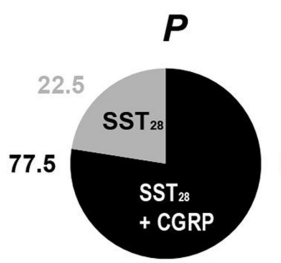

E

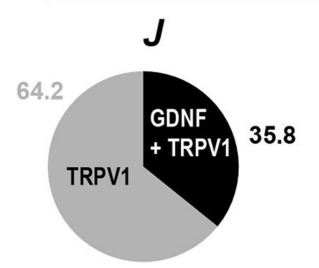

G
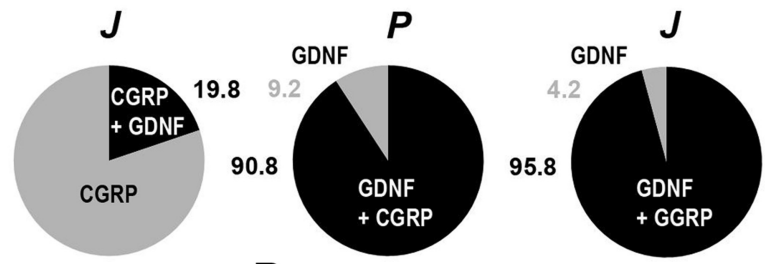

B
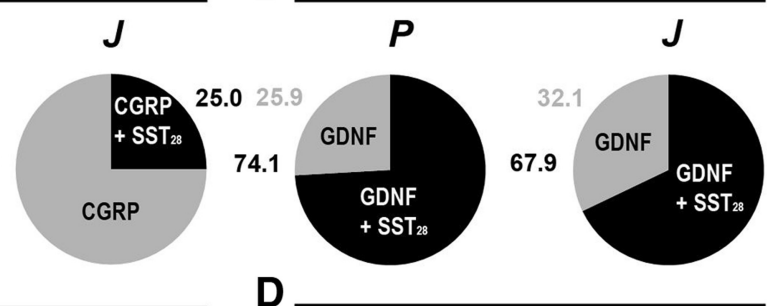

D

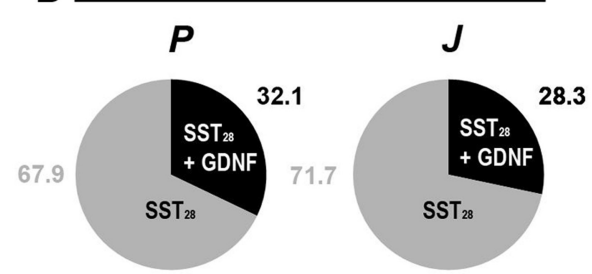

$\mathbf{F}$

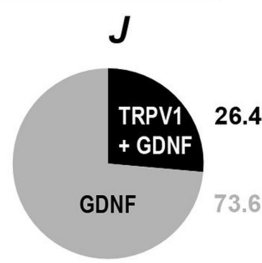

H

Figure 2. Pie charts showing the results of quantitative analysis on coexpression of GDNF and peptides (CGRP, SST 28 )/TRPV1 in DRGs. Mean numbers of cells counted per mouse $(n=3)$ were as follows: $307 \pm 11$ (CGRP + GDNF; P), $305 \pm 10$ (CGRP + GDNF;

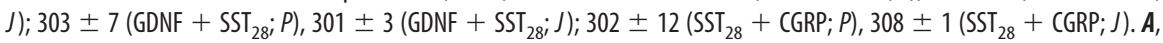
Percentages of CGRP-IR neurons expressing GDNF: $25.3 \pm 1.0(P)$ and $19.8 \pm 1.1(J)$. B , Percentages of GDNF-IR neurons expressing (GPR: $90.8 \pm 0.7 \%(P)$ and $95.8 \pm 0.1 \%(J)$. C, Percentages of CGRP-IR neurons expressing SST ${ }_{28}$ were $23.6 \pm 0.2(P)$ and $25.0 \pm 0.8(J)$. D, Percentages of GDNF-IR neurons expressing SST 28 were $74.1 \pm 4.2 \%(P)$ and $67.9 \pm 2.1(J)$. , Percentages of SST $_{28}-\mathrm{IR}$ neurons expressing CGRP were $77.5 \pm 1.9(P)$ and $92.9 \pm 0.4(J)$. $\boldsymbol{F}$, Percentages of $S S T_{28}$-IR neurons expressing GDNF were $32.1 \pm 1.2(P)$ and $28.3 \pm 1.3(J)$. Only mean values are reported in figure (coexpression, black; single labeling, gray). $\mathbf{G}-\boldsymbol{H}$, Percentage of GDNF-IR and TRPV1-IR neurons in juvenile mice (75 $\pm 21, n=4$ mice). $P$, postnatal; J, juvenile.

catalog AF482 RRID:AB_2301030), rabbit anti- TRPV1 (1:1000; Alomone Labs catalog ACC-030 RRID:AB_2040256), mouse anti- GFAP (1:500; Boehringer), and rabbit anti-phosphorylated (Thr 202/Tyr 204) extracellular signal-regulated kinases 1/2 (p-ERK1/2; 1:100; Santa Cruz Biotechnology; Kirshenbaum et al., 2011; Ferrini et al., 2014). An IB4biotin conjugate (Sigma) was also used (1:250 LM, 1:20 EM).

Routine immunocytochemical controls consisted in omission of primary antibodies (Salio et al., 2005). Pre-absorption (3 h at room temperature) of the anti-GDNF antibody used in immunocytochemical procedures with different concentrations of the immunizing peptide $(1-10 \mathrm{mg} / \mathrm{ml})$ resulted in a dose-dependent decrease of immunolabeling that was completely abolished at $2.5 \mathrm{mg} / \mathrm{ml}$.

Histology-LM. Anesthetized animals were perfused with Ringer's solution followed by $4 \%$ paraformaldehyde in $0.1 \mathrm{~m}$ phosphate buffer (PB).

The lumbar spinal cord segments L1-L6 and the corresponding DRGs were dissected out and immediately cut with a vibratome $(70 \mu \mathrm{m})$ or embedded in paraffin wax according to standard procedures (Salio et al., 2005).

Multiple immunofluorescence. Free-floating vibratome spinal cord sections and deparaffinized DRG sections were pre-incubated in $0.02 \mathrm{M}$ PBS containing $5 \%$ normal goat serum (PBS-5\% NGS) or PBS containing $6 \%$ bovine serum albumin (PBS-6\% BSA) for $30 \mathrm{~min}$, and then incubated overnight in appropriate mixtures of two to three primary antibodies. When it was necessary to use two primary antibodies raised in the same species, the paraformaldehyde vapor blocking method originally proposed by Wang and Larsson (1985) was used (Salio et al., 2005). Sections were then incubated for $1 \mathrm{~h}$ in a mixture of two to three appropriate fluorochromeconjugated secondary antispecies antibodies: IgG Alexa Fluor 488, 594, or 633 (1:500, Invitrogen). Sections were finally washed in PBS and mounted in Vectashield (Vector Laboratories).

Single-channel images were acquired using a Leica TCS SP5 confocal laser scanning microscope (Leica Microsystems) with appropriate filter settings and merged using Photoshop 7.0.1 (Adobe Systems).

Quantification of immunoreactive DRG neurons. A total of 18 lumbar DRGs from postnatal $(n=3)$ and juvenile CD1 male mice $(n=3)$ were serially sectioned in toto at $6 \mu \mathrm{m}$, and one of five sections in the series was used for immunostaining. Individual sections were double immunostained for one of the following combinations of primary antibodies: GDNF + CGRP, GDNF $+\mathrm{SST}_{28}, \mathrm{SST}_{28}+$ CGRP. Sections were photographed as single-stack images (capture images) at $20 \times$ with the confocal laser microscope, and pairs of digital images of the same microscopic field were obtained with appropriate filter combinations to visualize the fluorescence labels. Single- and/or doublelabeled DRG neurons were directly counted from dual-color fluorescence images obtained with the software Adobe Photoshop 7.0. Total numbers of cells are expressed as the mean/ animal of the cell counted from the three animals at each postnatal age ( \pm SEM). Results are expressed as the mean percentages $( \pm$ SEM) of double-labeled neurons versus the total number of single-labeled cells for each of the three combinations of primary antibodies. Quantification of GDNF + TRPV1 was performed on ganglia from four additional juvenile mice.

Histology-EM. Anesthetized animals were perfused with Ringer's solution followed by $4 \%$ paraformaldehyde $+0.1 \%$ glutaraldehyde + $0.2 \%$ picric acid in $0.2 \mathrm{M}$ sodium $\mathrm{PB}$ for postembedding EM immunocytochemistry (ICC) or $4 \%$ paraformaldehyde $+0.01 \%$ glutaraldehyde for pre-embedding EM ICC. Following pre-embedding ICC with FluoroNanogold (see below), L1-L6 spinal cord vibratome sections were conventionally embedded in Araldite after osmium postfixation and uranyl acetate en bloc staining. After freeze substitution for optimal antigenicity preservation (Altman et al., 1984), sections to be used in postembedding ICC of GDNF were instead embedded in Lowicryl HM20 resin (Chemische Werke Lowi) as follows: sections were slammed to a polished copper block cooled with liquid $\mathrm{N}_{2}$ in an MM80E cryofixation apparatus (Reichert), then transferred to $0.5 \%$ uranyl acetate dissolved in anhydrous methanol $\left(-90^{\circ} \mathrm{C}\right)$ in a freeze-substitution apparatus (CS Auto; Leica). The temperature was raised stepwise to $-50^{\circ} \mathrm{C}$. Samples were finally infiltrated with resin that was then polymerized by UV light (Cesa et al., 2003).

EM postembedding immunostaining. Araldite and Lowicryl ultrathin sections were cut with an ultramicrotome (EM UC6; Leica), immunostained on grids following conventional postembedding protocols (Merighi and Polak, 1993), and further counterstained with uranyl acetate and lead citrate before observation with a transmission EM (CM10; Philips). 


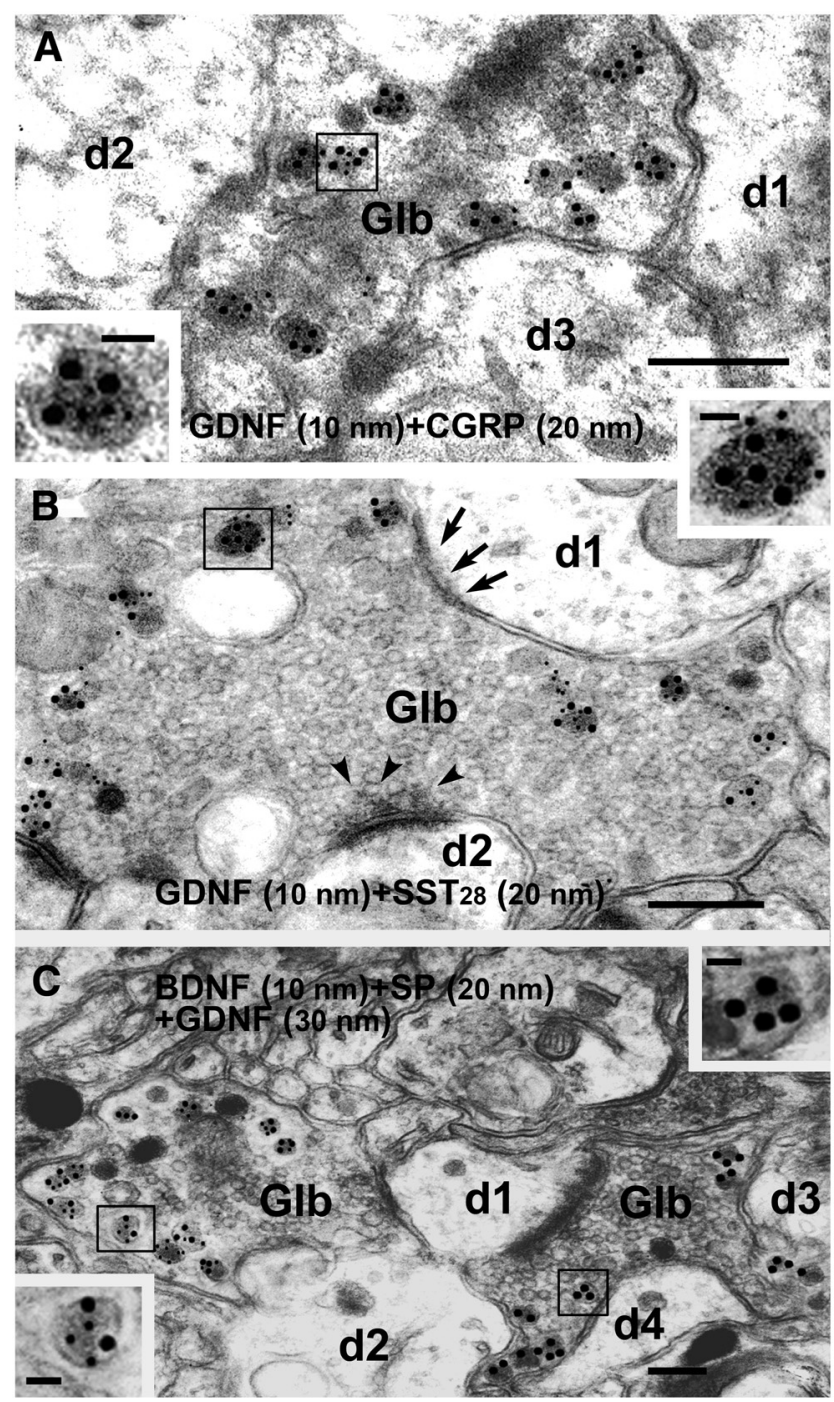

Figure 3. Ultrastructural localization of GDNF in spinal lamina II and colocalization with markers of peptidergic nPAFs after postembedding immunogold labeling. GDNF, BDNF, and peptides are selectively localized to DCVs, some of which are shown at higher magnifications in the inserts. Gold particle sizes are directly indicated on individual parts. For nomenclature of glomeruli and glomerular profiles, see Ribeiro-da-Silva (2004). $A$, A peptidergic C terminal in a Glb is double stained for GDNF and CGRP and surrounded by unlabeled dendrites (d1- $\mathrm{d} 3$ ). $B, A$ $\mathrm{GDNF}+\mathrm{SST}_{28}-\mathrm{IR}$ C terminal in GIb is surrounded by several unlabeled dendrites. The large $\mathrm{d} 1$ displays a symmetrical synapse (arrows), whereas the contact with d2 is an asymmetric synapse (arrowheads) with a well evident postsynaptic density. C, Two IR C terminals in Glbs are surrounded by several unlabeled dendrites ( $\mathrm{d} 1-\mathrm{d} 4)$ ). The terminal at left is double labeled for BDNF and SP (left insert), while the one on the right is only IR for GDNF (right insert). Scale bars: 250 $\mathrm{nm}$; inserts, $50 \mathrm{~nm}$.

EM pre-embedding immunostaining with FluoroNanogold. To preserve GFR $\alpha 1$ antigenicity, some free-floating L1-L6 spinal cord vibratome sections were immunostained with FluoroNanogold (Nanoprobes; Salio et al., 2011). Briefly, sections were incubated overnight in the anti-GFR $\alpha 1$ primary antibody at $4^{\circ} \mathrm{C}$, followed by $1 \mathrm{~h}$ incubation in anti-goat biotinylated IgG (Vector Laboratories), and, finally, an additional hour in Alexa Fluor 488-FluoroNanogold-Streptavidin (Nanoprobes). Sections were then processed with a Gold Enhancement Kit (Nanoprobes) to increase the size of the gold tag and embedded in Araldite for further cutting. Some of these ultrathin sections were also stained for IB4 following the postembedding immunostaining protocol described above.

Quantification of immunoreactivity neuronal profiles in SDH. Counts of immunoreactivity (IR) profiles to assess the distribution and relative levels of GDNF and IB4 in double-labeling experiments were directly performed on 90 randomly selected, ultrathin sections obtained from juvenile mice $(n=3)$. A total of 819 grid squares was examined. To obtain an exact definition of the distribution of immunostaining in individual sublaminae within lamina II (Ribeiro-da-Silva, 2004; Ribeiroda-Silva and De Koninck, 2008), immunolabeled terminals were classified on the basis of their ultrastructure and distance from the dorsal margin of the spinal cord. To do so, counts were performed within individual $90 \times 90 \mu \mathrm{m}$ squares of 200 mesh EM grids by choosing those fields where the pial surface was in contact with one of the grid bars and moving perpendicularly toward the depth of SDH. In this way it was possible to cover the entire dorsoventral extent of lamina II.

The percentages of GDNF + CGRP $+\mathrm{SP}, \mathrm{GDNF}+\mathrm{SST}_{28}+\mathrm{SP}$, and $\mathrm{SST}_{28}+\mathrm{CGRP}+$ SP triple-immunolabeled terminals $(n=150$ for each combination of primary antibodies) in SDH were calculated on 25 randomly selected, ultrathin sections obtained from juvenile mice $(n=4)$ for each of the three combinations of the three antigens. The percentages of GFR $\alpha 1$-IR profiles were calculated on 24 randomly selected ultrathin sections. Profiles $[n=50$ each from postnatal $(n=4)$ and juvenile mice $(n=4)]$ were classified as axon terminals, perikarya, or dendrites according to previously described morphological criteria (Peters et al., 1991).

Spinal cord slices preparation. The L1-L6 spinal cord was rapidly dissected out from anesthetized mice and $350-\mu \mathrm{m}$-thick transverse slices were obtained with a vibrating microtome (VT1200; Leica Microsystems). For $\mathrm{Ca}^{2+}$-imaging experiments, the dissection was performed in ice-cold cutting solution containing the following (in mM): 222 sucrose, $2.6 \mathrm{KCl}, 26 \mathrm{NaHCO}_{3}, 1 \mathrm{NaH}_{2} \mathrm{PO}_{4}, 0.5 \mathrm{CaCl}_{2}, 7 \mathrm{MgSO}_{4}$, and 0.1 ascorbic acid. Slices were then allowed to recover at $35^{\circ} \mathrm{C}$ for $30 \mathrm{~min}$ in artificial CSF (aCSF) containing the following (in $\mathrm{mm}$ ): $123 \mathrm{NaCl}, 3 \mathrm{KCl}, 26$ $\mathrm{NaHCO}_{3}, 1 \mathrm{NaH}_{2} \mathrm{PO}_{4}, 10$ glucose, $1.5 \mathrm{MgSO}_{4}$, and $2 \mathrm{CaCl}_{2}$, saturated with $95 \% \mathrm{O}_{2}-5 \% \mathrm{CO}_{2}$. For patch-clamp experiments, slices were cut and recovered in aCSF containing the following (in mM): $125 \mathrm{NaCl}, 2.5 \mathrm{KCl}$, $25 \mathrm{NaHCO}_{3}, 1 \mathrm{NaHPO}_{4}, 25$ glucose, $1 \mathrm{MgCl}_{2}$, and $2 \mathrm{CaCl}_{2}$, saturated with $95 \% \mathrm{O}_{2}-5 \% \mathrm{CO}_{2}$.

Single-cell $\mathrm{Ca}^{2+}$ imaging. After recovering, slices were collected on the porous membrane of a Millicell-CM insert (Millipore), placed into a 35 $\mathrm{mm}$ Petri dish, and covered by a loading solution containing $2 \mu \mathrm{l}$ of Oregon Green 488 BAPTA-1AM ( $50 \mu \mathrm{g}$ of Oregon Green in $4 \mu \mathrm{l}$ DMSO; Invitrogen), $1 \mu$ l pluronic acid (20\% Pluronic F-127 in DMSO; Invitrogen), and $4 \mu \mathrm{l}$ Cremophor (0.5\% Cremophor EL in DMSO; Sigma) in 1 $\mathrm{ml}$ oxygenated aCSF. An additional $1 \mathrm{ml}$ of oxygenated aCSF was pipetted below the membrane in the Petri dish. Loading was performed in the dark, at $37^{\circ} \mathrm{C}$ for $45-50 \mathrm{~min}$, during which $95 \% \mathrm{O}_{2}$ and $5 \% \mathrm{CO}_{2}$ were continuously supplied under moist conditions. Slices were then washed in fresh oxygenated aCSF and maintained at room temperature until imaging in a recording chamber mounted on the stage of a Leica TCS SP5 confocal microscope equipped with $40 \times$ water-immersion objectives. During image acquisition, slices were continuously perfused with oxygenated aCSF $(2 \mathrm{ml} / \mathrm{min})$. Lamina II appeared translucent in the transmission mode and the gray matter above it was identified as lamina I. Oregon Green fluorescence was excited at $488 \mathrm{~nm}$, and emission was acquired at 495-530 $\mathrm{nm}$. Gain, offset, and pinhole were kept constant during acquisition. Images were sampled at $2 \mathrm{~s}$ frame intervals. At the end of each experiment, cell viability was assessed by $60 \mathrm{~mm} \mathrm{KCl}$ challenge and only KCl-responsive neurons were subjected to analysis (Pasti et al., 1997).

Relative fluorescence intensity $\left(\Delta F / F_{0}\right)$ was measured in individual neuronal perikarya as the variation of fluorescence intensity $\Delta F$ versus the baseline fluorescence $F_{0}$, where $F_{0}$ was defined as the mean fluorescence intensity observed for $1 \mathrm{~min}$ before pharmacological stimulation. Neurons with $\Delta F / F_{0}$ values $\geq 0.2$ ( $\geq 20 \%$ of fluorescence increase) were assigned as responsive. Raw data were smoothed by averaging three consecutive data points. The integral of the curve of the relative fluorescence intensity plotted against time (AUC $=$ area under the curve) was calculated for each cell within the period corresponding to the duration of the effect, the incurring time from the onset of the effect $\left(\Delta F / F_{0} \geq 0.2\right)$ to the recovery of the fluorescence at the baseline level $\left(F_{0}\right)$. Amplitude changes and duration of the response were measured in excel spreadsheets (Mi- 


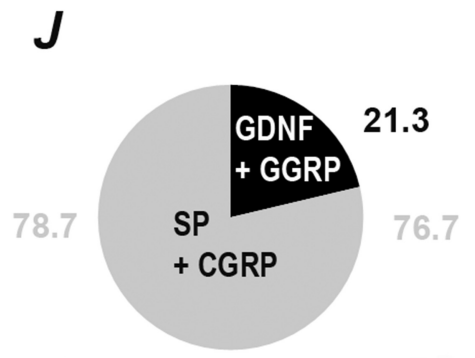

A

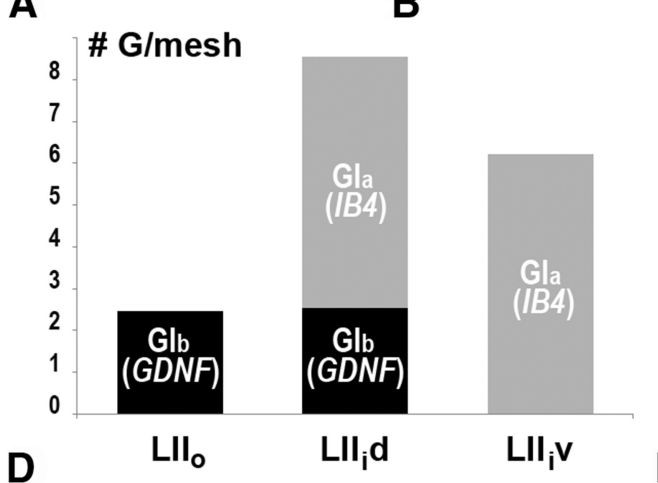

B
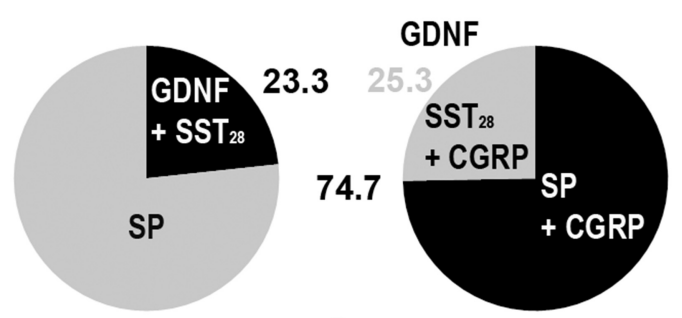

C
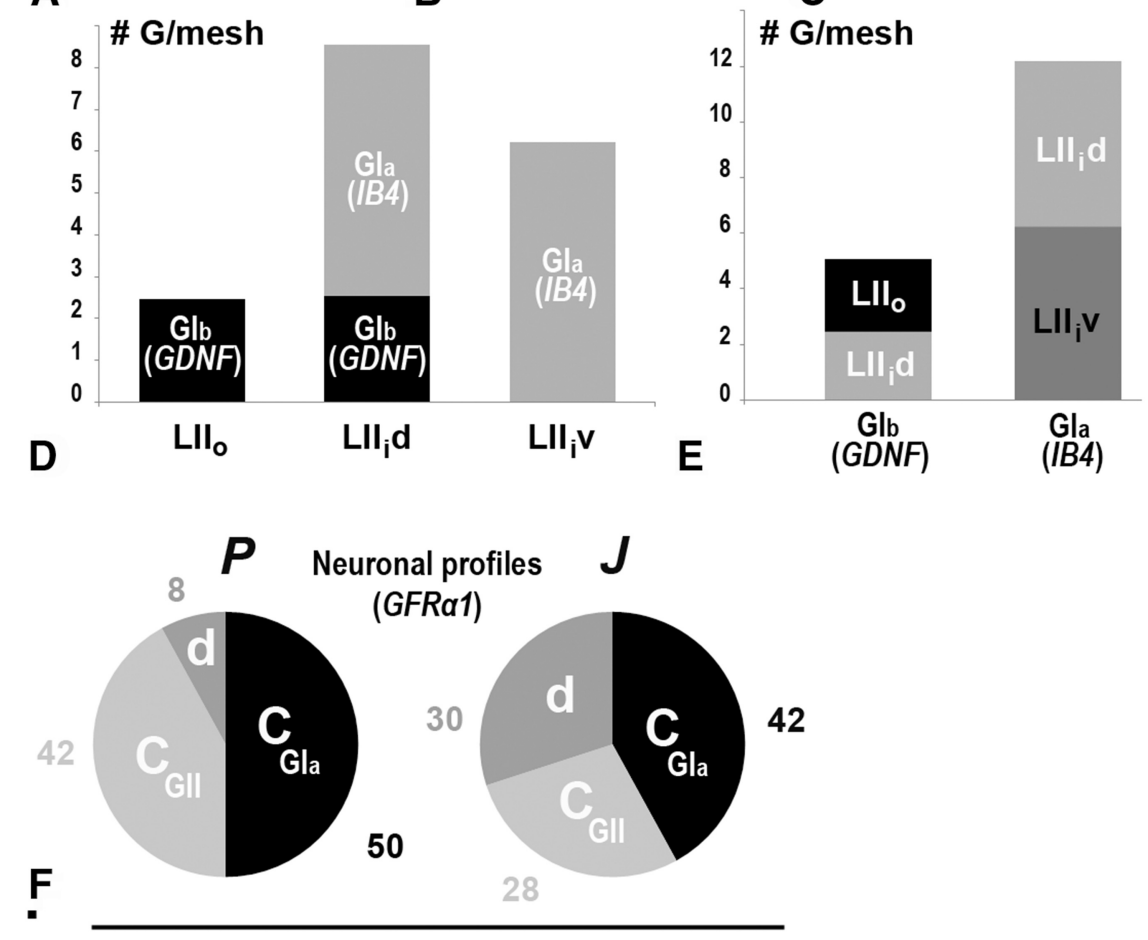

Figure 4. Pie and bar charts showing the results of ultrastructural quantitative analysis on distribution of GDNF and related molecules in SDH. $A-C$, Percentages of the different patterns of colocalization after triple labeling with GDNF + CGRP + SST $_{28}$ antibodies ( $n=150$ profiles per pie). $\boldsymbol{D}, \boldsymbol{E}$, Density of glomeruli (number per grid mesh) in different sublaminae of lamina ll after double labeling with GDNF + IB4 expressed in a function of localization (D) or type of glomerulus per marker $(\boldsymbol{E})$. Boundaries of sublaminae have been determined by measuring the distances from the dorsal margin of spinal cord (LII $: 25-45 \mu \mathrm{m}$; LII $\mathrm{d}$ : 45-65 $\left.\mu \mathrm{m} ; \mathrm{LII}_{\mathrm{i}} \mathrm{v}: 65-90 \mu \mathrm{m}\right)$. $\boldsymbol{F}$, Percentages of GFR $\alpha 1$-IR profiles in SDH from postnatal $(P)$ and juvenile $(J)$ mice $(n=50$ profiles per pie). (Gla, central boutons in Gla; (GII, central boutons in GII; d, dendrites; G, glomeruli. See Ribeiro-da-Silva, 2004 for nomenclature of glomeruli and sublaminae of lamina II.

crosoft), and AUC was calculated with Origin Microcal software (OriginLab).

Patch-clamp recordings. Whole-cell recordings were performed as previously described from SDH neurons held at $-70 \mathrm{mV}$ (Ferrini et al., 2007). EPSCs were recorded with a pipette solution containing the following (in mM): $145 \mathrm{Cs}$ methanesulfonate, 5 EGTA, $2 \mathrm{MgCl}_{2}, 10$ HEPES, 2 ATP.Na, 0.2 GTP.Na, and 0.1\% Lucifer yellow (LY; Sigma), $\mathrm{pH}$ 7.2. LY was added to trace the position of recorded neurons within the SDH. mEPSCs were isolated in the presence of tetrodotoxin (TTX; $1 \mu \mathrm{M})$. Recordings were obtained with a Multiclamp700B amplifier (Molecular Devices), sampled at $10 \mathrm{kHz}$, and filtered at $2.4 \mathrm{kHz}$. They were included for subsequent analysis only if access resistance was stable throughout the patch-clamp session. Analysis was performed off-line with Mini Analysis software (Synaptosoft). Amplitude and frequency of mEPSCs in control traces and after capsaicin application were compared within $100 \mathrm{~s}$ time intervals, using the KolmogorovSmirnov test. Neurons were classified as responsive when the distribution of interevent interval and/or amplitude values following capsaicin administration were significantly different compared with control $(p<0.01)$. Electrophysiological data were expressed as a percentage of the predrug control value \pm SEM, with $n$ indicating the number of neurons.

Acute slice immunostaining after capsaicin stimulation. Slices were incubated in the following: (1) aCSF (control), (2) $2 \mu \mathrm{M}$ capsaicin for $5 \mathrm{~min}$, (3) anti-GDNF neutralizing antibody $(10 \mu \mathrm{g} / \mathrm{ml}$; R\&D Systems; Battaglia et al., 2009) for $10 \mathrm{~min}$, and (4) $2 \mu \mathrm{M}$ capsaicin (5 $\mathrm{min})$ in the presence of the anti-GDNF neutralizing antibody. Slices were then maintained in oxygenated aCSF for $15 \mathrm{~min}$ (ERK1/2 phosphorylation assay) or $60 \mathrm{~min}$ (capsaicininduced release assay). Slices were then fixed and processed as described above for histological procedures and IF with appropriate combinations of primary and secondary antibodies (further details can be found in Ferrini et al., 2014).

Confocal images were obtained with a $20 \times$ objective. Immunostained slices were sequentially scanned along the $z$-axis in $2 \mu \mathrm{m}$ steps. For quantifying peptide and growth factor depletion after capsaicin stimulation, the optical section with the highest fluorescence intensity in each stack (as measured by the Leica SP5 software) was chosen and the mean fluorescent intensity of GDNF and SP signals within a polygonal region of interest delimiting the $\mathrm{SDH}$ was measured. For quantifying p-ERK1/2-IR, the five highest signal-intensity consecutive optical sections from a stack were combined, and the percentage surface of the SDH occupied by $\mathrm{p}$-ERK1/2 staining was measured using Image J software (http://rsbweb.nih.gov/ij/docs/faqs.html\#cite).

ELISA. The L1-L6 spinal cord segments from four postnatal P8-P12 mice were dissected out as above and 700- $\mu \mathrm{m}$-thick transverse slices were obtained with a tissue chopper (Brinkmann Instruments). After $30 \mathrm{~min}$ recovery, slices were either left in aCSF or treated with capsaicin ( $2 \mu \mathrm{M}$ to $5 \mathrm{~min}$ ). Slices were then removed from medium, snap frozen in liquid nitrogen, and mechanically homogenized in $100 \mu \mathrm{l}$ of lysis buffer containing (in mM): 150 $\mathrm{KCl}$, $20 \mathrm{HEPES}, 5 \mathrm{MgCl}_{2}$, and 0.5 DTT). After centrifugation $(10,000 \times g$ for $20 \mathrm{~min})$, supernatant was collected and total protein content measured by the Bradford assay. ELISA was performed in duplicate using a GDNF immunoassay kit and following manufacturer's instructions (Abnova; KA3041).

Drugs. Drugs included the following: GDNF (100 ng/ml; PeproTech), capsaicin ( $2 \mu \mathrm{M}$; Sigma), phosphatidylinositol-specific phospholipase C (PI-PLC; $1 \mathrm{U} / \mathrm{ml}$; Sigma), AP5 (50 $\mu \mathrm{M}$; Tocris Bioscience), and TTX (1 $\mu \mathrm{M}$; Tocris Bioscience). All drugs were bath applied after being dissolved in aCSF at the concentrations indicated above.

Statistics. Quantitative variables are expressed as mean \pm SEM. Student's $t$ test or Wilcoxon tests were used to compare, respectively, normal and non-normal distributed raw data. Kruskal-Wallis or Mann-Whitney tests were used to compare normalized and percentage data. Differences were considered significant for $p<0.05$.

\section{Results}

Expression of GDNF in DRG and spinal cord

We found that a subset of small- to medium-sized DRG neurons was GDNF-IR. These neurons were a subpopulation of CGRP-IR neurons (Fig. 1A) that also expressed $\mathrm{SST}_{28}$ (Fig. 1B). Conversely, 
GDNF-IR neurons were found not to express SP (Fig. 1C) and BDNF (Fig. 1D) or to be stained by IB4 (Fig. 1E). A fraction of the GDNF-IR neurons also expressed the capsaicin receptor TRPV1 (Fig. $1 F$ ). Quantitative data are reported in chart form in Figure 2.

There were no GDNF-IR neuronal cell bodies in DH. GDNF-IR fibers belonged to a subpopulation of peptidergic nociceptive PAFs (nPAFs) containing CGRP (Fig. $1 G$ ) and $\mathrm{SST}_{28}$ (Fig. $1 H$ ), whereas the BDNF-IR (Fig. 1I) and SP-IR (Fig. 1J) peptidergic nPAFs (Salio et al., 2007), as well as the IB4 + nonpeptidergic nPAFs (Fig. $1 K$ ), were devoid of GDNF-IR. Therefore, in SDH, GDNF-IR was restricted to a band of processes in lamina II, between the more dorsal band of SP-IR processes and the more ventral band of those labeled by IB4 (Fig. 1L). Double IF experiments also demonstrated that GDNF was not expressed in GFAP-IR astrocytes (Fig. 1M).

At the EM level, the central terminals (C terminals) of PAFs form typical multisynaptic complexes that are commonly referred to as glomeruli. Glomeruli are a prominent ultrastructural feature of lamina II, the substantia gelatinosa, and exist in at least two main types in rodents (Ribeiro-daSilva, 2004). Our EM-immunolabeling experiments demonstrated that GDNF-IR was selectively localized to the dense core vesicles (DCVs) that were contained in the $\mathrm{C}$ terminals of the glomeruli of the type Ib (GIb) formed by the peptidergic nPAFs (Ribeiro-da-Silva, 2004). Ultrastructurally, we were able to confirm the combinations of neurochemicals observed in PAFs at the confocal microscope (Fig. 3) and to calculate the percentages of the two main subtypes (SP-IR vs $\mathrm{SST}_{28^{-}}$ IR) of GIb glomeruli in relation to GDNF expression (Fig. 4A-C). Our EM analysis also confirmed the absence of GDNF im-

munolabeling in nonpeptidergic nPAF terminals, which are known to form the C-terminal boutons in IB4 + type Ia glomeruli (GIa; Bailey and Ribeiro-da-Silva, 2006; Fig. 8). In addition, we used EM ICC to confirm our IF observations at the confocal microscope that were suggestive of a very precise sublaminar localization of GDNF within lamina II (Fig. $1 L$ ) according to its tripartite subdivision proposed by Ribeiro-da-Silva (2004) in rat. Therefore, we counted GDNF-IR C terminals in GIb and IB4+ C terminals in GIa related to their position in lamina II that contains GIb (lamina II outer; LII ), mixed GIa/GIb (lamina II inner dorsal; $\mathrm{LII}_{\mathrm{i}} \mathrm{d}$ ), or GIa (lamina II inner ventral; $\mathrm{LII}_{\mathrm{i}} \mathrm{v}$ ) along a dorsoventral axis. The data obtained demonstrated that GDNF-IR glomeruli had a similar incidence in laminae $\mathrm{LII}_{\mathrm{o}}$ and $\mathrm{LII}_{\mathrm{i}} \mathrm{d}$ (Fig. $4 D, E$ ).

In brief, these results confirm the initial reports on GDNF or GDNF mRNA localization in DRGs and spinal cord but extend these observations to (1) the pattern of coexistence (LM) and colocalization (EM) with CGRP/SST ${ }_{28}$. As to this issue, it is note-
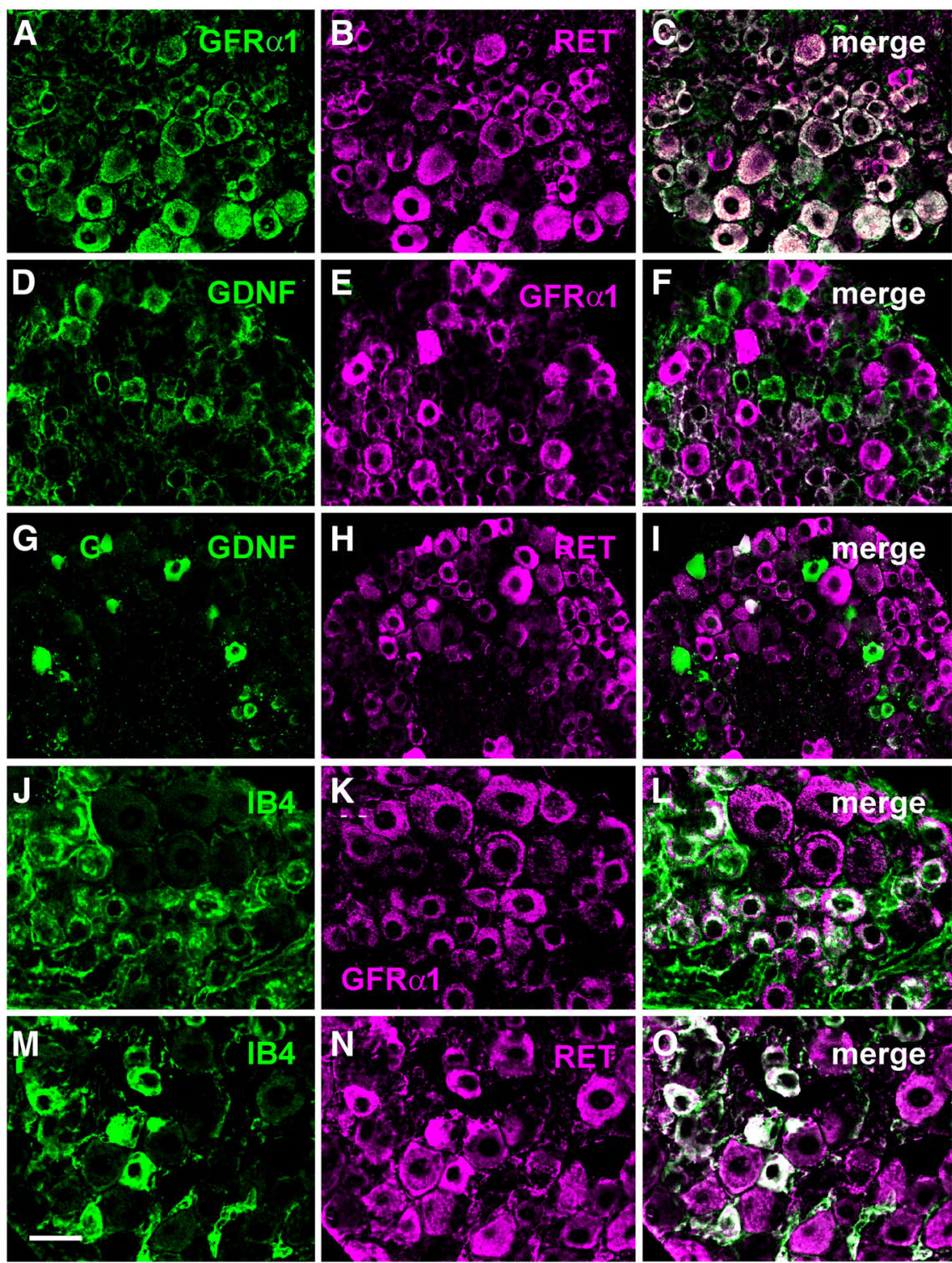

Figure 5. Distribution of the GDNF receptor complex in DRGs and pattern of expression with the marker of nonpeptidergic nociceptors IB4. $\boldsymbol{A}-\boldsymbol{C}, \mathrm{GFR} \alpha 1$ - and RET-IR are coexpressed in a large population of neurons of different sizes. GDNF is not coexpressed in GFR $\alpha 1$-IR neurons $(\boldsymbol{D}-\boldsymbol{F})$ and rarely coexpressed in RET-IR neurons $(\boldsymbol{G}-\boldsymbol{I})$. An evident fraction of GFR $\alpha 1$-IR neurons $(\boldsymbol{J}-\mathbf{L})$ or RET-IR neurons $(\boldsymbol{M}-\mathbf{0})$ is instead labeled with IB4. Scale bar, $50 \mu \mathrm{m}$.

worthy that LM and EM quantitative data in juvenile animals are remarkably overlapping (GDNF + CGRP: DRG neurons 19.8\%; Fig. 2A, J; glomeruli 21.3\%; Fig. $4 A$; $\mathrm{SST}_{28}+$ CGRP: DRG neurons 25\%; Fig. 2C,J; glomeruli 25.3\%; Fig. $4 C$ ) and thus indicative of a relationship between the numbers of IR-glomeruli and their parent cell bodies in DRGs; These observations are also extended to the following: (2) the sublaminar localization of IR profiles in lamina II and (3) the type(s) of IR profiles after EM analysis.

Expression of GDNF receptors in DRG and spinal cord

Figures 5 and 6 show the pattern of distribution of the GDNF receptor complex components in DRG neurons and its relationship with GDNF and specific markers of nociceptors. There was a high degree of coexpression of GFR $\alpha 1$ and RET in DRG neurons of heterogeneous sizes, supporting the possibility that functionally different sensory neurons may be targets of GDNF (Fig. $5 A-C)$, whereas ligand and receptor coexpression did not occur (GFR $\alpha 1$; Fig. $5 D-F$ ) or was quite rare (RET;Fig. $5 G-I$ ). 

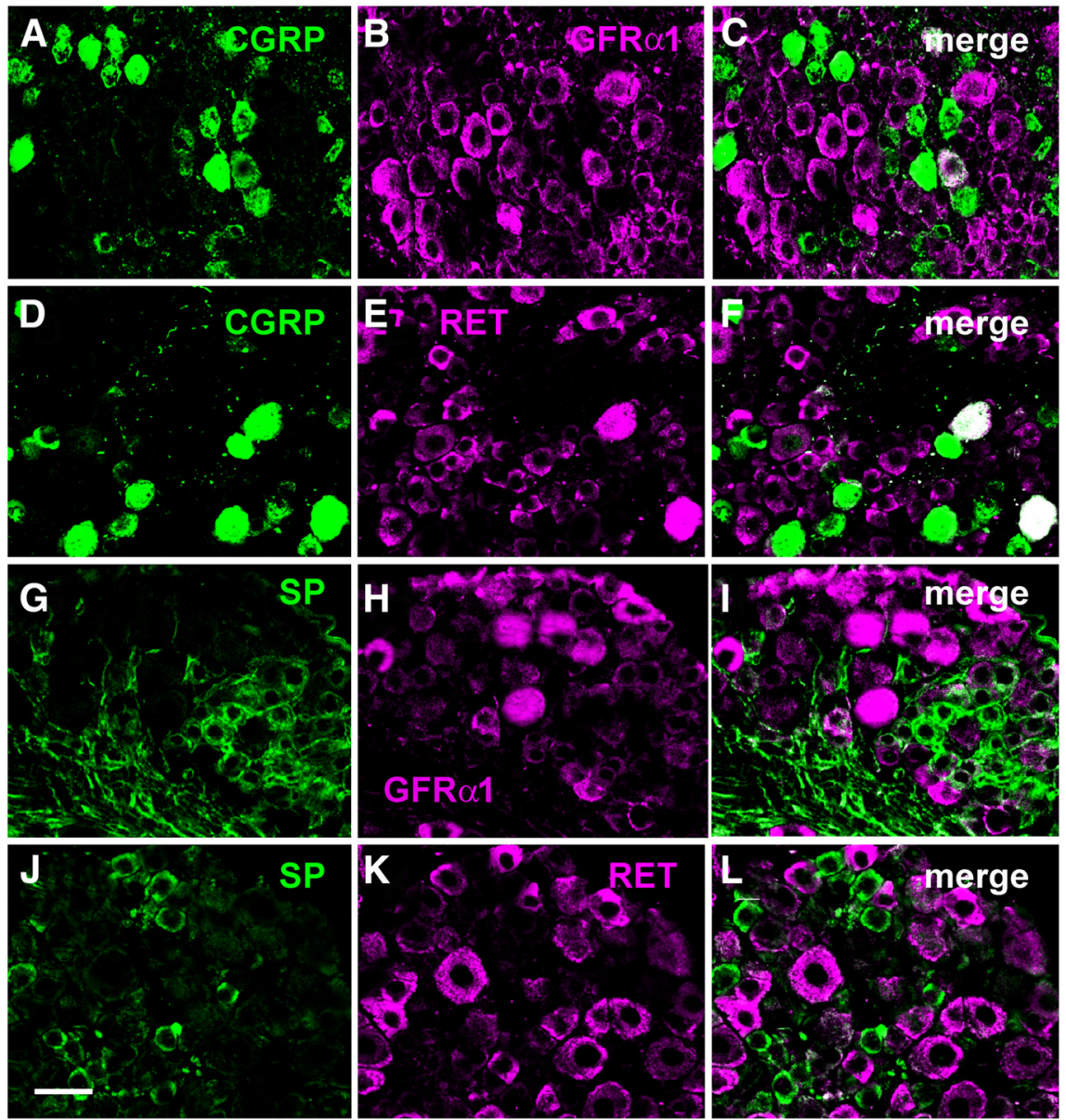

Figure 6. Distribution of the GDNF-receptor complex in DRGs and pattern of expression with peptidergic (CGRP/SP) nociceptors. A very limited number ofCGRP-IRneurons expresses GFR $\alpha 1$ (A-C) or RET (D-F).SP-IRneurons do notdisplay GFR $\alpha 1-I R(G-I)$ or RET-IR (J-L).Scalebar, $50 \mu \mathrm{m}$.
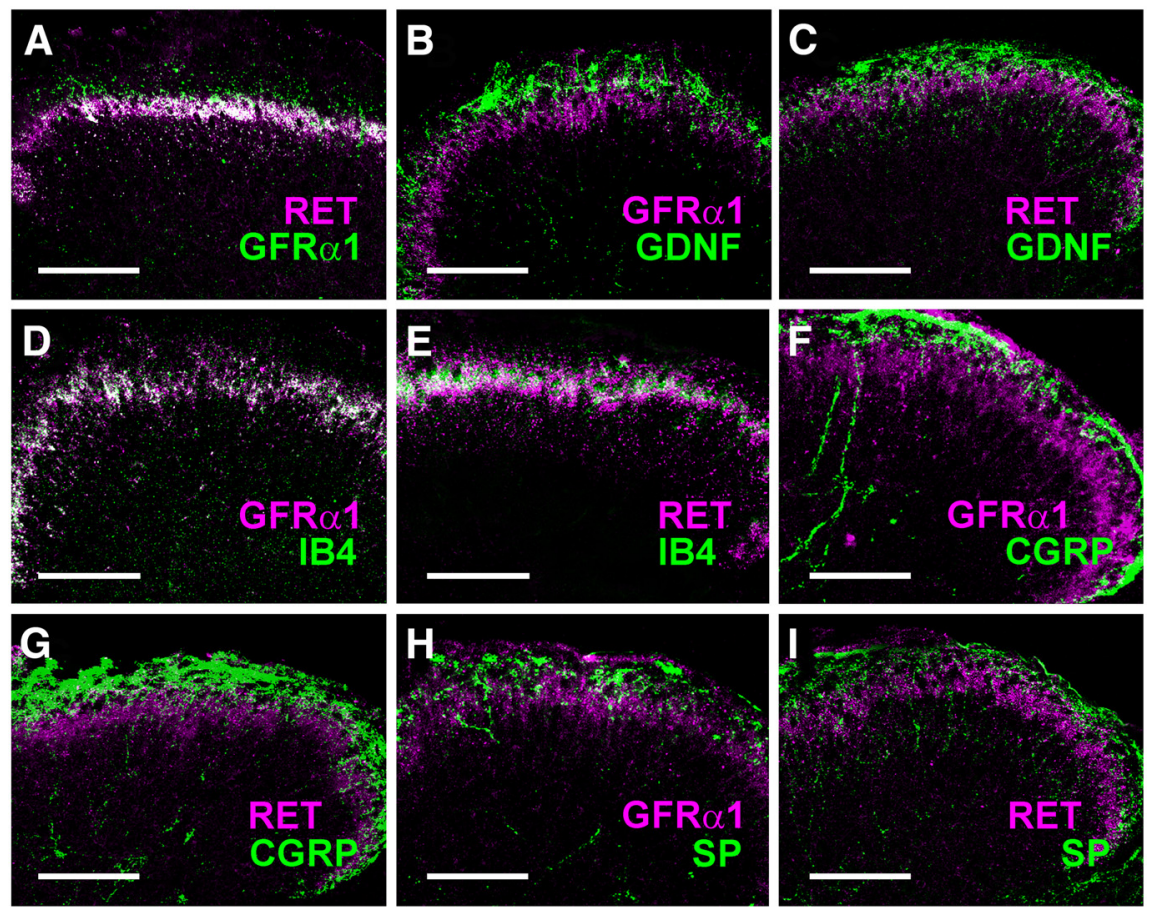

Figure 7. Expression of the GDNF and its receptor complex in dual-color IF images (magenta + green) of the DH. GFR $\alpha 1$ and RET are coexpressed (white) in lamina II $(\boldsymbol{A})$ whereas there is no coexpression with $\operatorname{GDNF}(\boldsymbol{B}, \boldsymbol{C})$ throughout the DH. Lamina Il displays fibers that are double labeled for GFR $\alpha 1+$ IB4 (D) or RET + IB4 (E).F-I, CGRP-IRandSP-IR fibers do not displayGFR $\alpha 1$-IRor RET-IR. Scale bars: $250 \mu \mathrm{m}$.
Each of the two components of the receptor complex was instead localized in a wide subset of IB4+ DRG neurons (Fig. 5J$O)$, but virtually or totally absent in the neurons that express CGRP (Fig. 6A-C, GFR $\alpha 1$; Fig. $6 D-F$, RET) or SP (Fig. $6 G-I$, GFR $\alpha 1$; Fig. $6 J-L$, RET). The immunocytochemical distribution of GFR $\alpha 1$ and RET in the SDH and the pattern of colocalization with markers of peptidergic and nonpeptidergic nPAFs is shown in Figure 7.

Ultrastructurally, we only detected GFR $\alpha 1$ receptors that, within the $\mathrm{SDH}$, were observed in GIa (Fig. 8A), GII (Fig. $8 B$ ), and plain dendrites (Fig. $8 C$ ). Notably, terminals in GIa were also IB4+ (Fig. 8A).

Again our observations not only are confirmative of previous reports on GFR $\alpha 1$ / RET protein/mRNA localization in DRGs and spinal cord, but extend them to the types of IR profile and their pattern of coexistence with IB4 at the ultrastructural level.

\section{Age-related modifications}

Figure 2 displays in graph form the results of a quantitative analysis on the localization of GDNF in peptidergic nociceptors expressing CGRP or $\mathrm{SST}_{28}$. It is well known that $\mathrm{SST}_{28}+$ DRG neurons represent a subset of the CGRP+ small- to medium-sized, dark peptidergic neurons. We show here that remarkably similar fractions of CGRP + DRG neurons are also IR for GDNF or $\mathrm{SST}_{28}$ in postnatal animals (Fig. $2 A-P$ ). The latter undergoes a slight increase in juvenile mice (Fig. 2C), in parallel with the strong reduction (from 22.5 to $7.1 \%$ ) in the fraction of $\mathrm{SST}_{28}$-IR neurons that do not contain CGRP (Fig. 2E). On the other hand, the percentage of GDNF and CGRP doublelabeled DRG neurons undergoes a reduction (from 25.3 to $19.8 \%$ ) with respect to the total population of CGRP-IR cells (Fig. 2A), although an opposite trend is observed when the number of GDNF and CGRP double-labeled DRG neurons is instead related to the total number of the GDNF-IR cells (from 90.8 to $95.8 \%$; Fig. $2 B)$. Overall analysis in Figure 2 indicates that as the system matures there is a slight reduction of the peptidergic subpopulation of DRG neurons expressing GDNF (Fig. 2A,F), at the expense of the degree of coexistence of GDNF and $\mathrm{SST}_{28}$ (Fig. 2D).

Quantitative analysis (Fig. $4 F$ ) of the ultrastructural pattern of distribution of GFR $\alpha 1$-IR profiles in lamina II showed that, in postnatal mice, there was a net predominance of GFR $\alpha 1$ presynaptic labeling in C PAF terminals (92\%), which remained remarkably high $(70 \%)$ also in juvenile animals. 

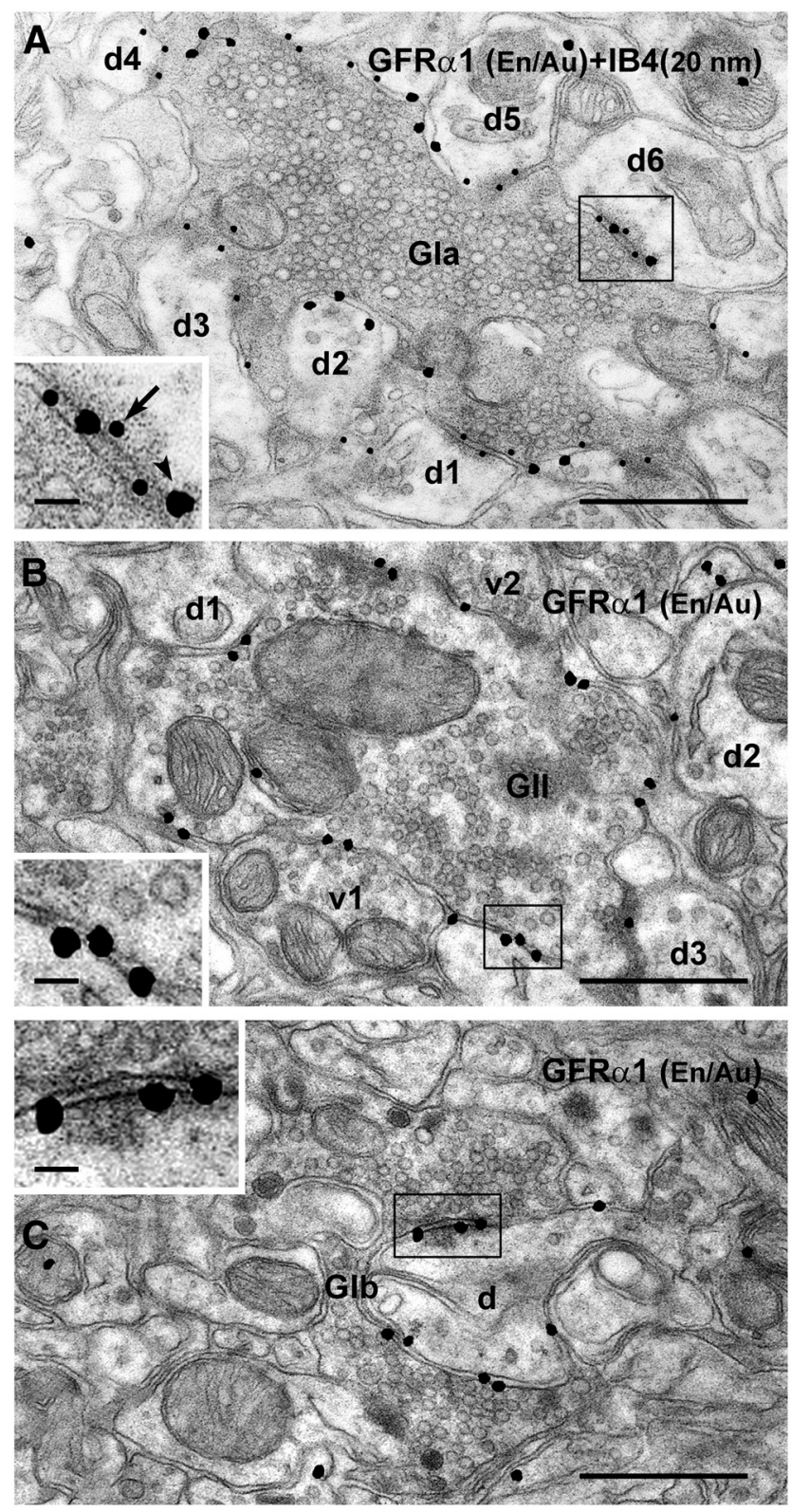

Figure 8. Ultrastructural localization of GFR $\alpha 1$ in lamina II and colocalization with the nonpeptidergic marker IB4 after combined pre-embedding immunogold labeling with goldintensified (En/Au) FluoroNanogold (GFR $\alpha 1$ ) and postembedding immunostaining (IB4). For nomenclature of glomeruli and glomerular profiles, see Ribeiro-da-Silva (2004). $\boldsymbol{A}$, Doublelabeled $\mathrm{C}$ terminal in a Gla surrounded by several unlabeled dendrites (d1- $\mathrm{d} 6$ ). Gold particles are localized over the plasma membrane of the terminal, and the two labels can be distinguished since GFR $\alpha 1$-IR is characterized by irregular gold-intensified gold particles (25-30 nm; arrowhead in the insert), while IB4+ membranes are decorated by the presence of round, regular gold particles of constant size ( $20 \mathrm{~nm}$; arrow in the insert). $\boldsymbol{B}, \mathrm{A}$ GFR $\alpha 1-\mathrm{IR}$ C terminal in GII contacts several unlabeled dendrites ( $(\mathrm{d} 1-\mathrm{d} 3)$, a peripheral axonal bouton (V2), and a vesicle-containing dendrite (v1). Gold particles are distributed over the plasma membrane, at both synaptic and nonsynaptic sites (insert). C, A GFR $\alpha 1$-labeled dendrite is postsynaptic to an unlabeled Glb. Scale bars: $500 \mathrm{~nm}$; inserts: $\boldsymbol{A}, \boldsymbol{B}, 20 \mathrm{~nm}$.

These observations indicate that the GDNF-GDNF receptor complex undergoes a certain degree of rearrangement in parallel with the maturation of the somatosensory system, particularly regarding the coexpression of GDNF and $\mathrm{SST}_{28}$ in DRGs. This observation is strengthened by the results of ultrastructural analysis of triple-immunolabeled glomeruli in lamina II (Fig. $4 A-C$ ). In particular, our results were as follows:(1) they confirm that, as in rat, mouse peptidergic (CGRP+) GIb glomeruli form two separate subpopulations containing either SST or SP (Ribeiroda-Silva, 2004) and (2) they show GDNF and SST $_{28}$ colocalization in a fraction (23.3\%; Fig. $4 B)$ of these glomeruli that is close to the figure calculated in rat $(\sim 30 \%)$ for SST-containing GIb profiles.

Nonetheless, rat and mouse comparisons are difficult because, as mentioned in the Introduction, the majority of previous work (in rat) was focused on the survival/neuroprotective effect of the GDNF, and no data are available-at least to our knowledge-on the coexpression of GDNF and SST in DRGs. More data are available relative to the GDNF receptor complex, particularly on the distribution of GFR $\alpha 1$, but the overall picture is further complicated by the fact that DRGs and spinal cord also express GFR $\alpha 2$. It seems highly questionable that GDNF interacts in vivo with ligands other than GFR $\alpha 1$ (Carmillo et al., 2005). In addition, specific types of low-threshold mechanoreceptors are identified by a unique coexpression of the RET and GFR $\alpha 2$ (Bourane et al., 2009; Hu et al., 2012). As it seems unlikely that nociceptors display this pattern of receptor coexpression, we have not considered here the distribution of GFR $\alpha 2$. Studies in rat have shown that GFR $\alpha 1$ is mainly expressed in lamina $\mathrm{II}_{\mathrm{o}}$ and GFR $\alpha 2$ in lamina $\mathrm{II}_{\mathrm{i}}$ of the lumbar (Keast et al., 2010) and sacral spinal cord (Forrest and Keast, 2008). However, other authors notably concluded that GFR $\alpha 2$ was not found in the adult human spinal cord and that GDNF and GFR $\alpha 2$ mRNAs were only expressed at detectable levels in fetuses (Josephson et al., 2001). These are additional reasons to exert prudence in comparing data between species, including humans (Price and Flores, 2007).

Irrespective of this, we cannot exclude that a subpopulation of fibers in SDH also expresses GFR $\alpha 2$, and that GFR $\alpha 2+/ \mathrm{GFR} \alpha 1-/$ $\mathrm{RET}+\mathrm{DRG}$ neurons and C terminals occur in mouse, but we can safely affirm that the population of GFR $\alpha 1$-expressing fibers in this species is not localized to lamina $\mathrm{II}_{\mathrm{o}}$.

\section{Endogenous GDNF is released from nPAFs and activates SDH neurons in a spinal cord slice preparation}

In previous work (Vergnano et al., 2008) we have demonstrated that the application of the TRPV1 agonist capsaicin onto acute spinal cord slices is a useful model in vitro to induce the central release of the nociceptive messengers that are liberated in inflammatory pain. These data have been reinforced by the subsequent observation that activation of type $\mathrm{C}$ nPAFs in this slice preparation is accompanied by a neuronal response in SDH (Bencivinni et al., 2011). Here, we found that a fraction of the GDNF-IR neurons in DRGs also expressed TRPV1 (Figs. 1F, 2G). Therefore we reasoned that the capsaicin-induced activation of nPAFs was likely capable of releasing in vitro the pool of endogenous GDNF from terminals (Fig. 5A-D). Indeed, capsaicin administration induced a strong reduction of GDNF-IR ( $p=0.006, t$ test) and SP-IR ( $p=0.0001, t$ test) in SDH. Additionally, decrease of the GDNF content in spinal cord following acute capsaicin stimulation was confirmed by ELISA (Fig. 9E). These experiments demonstrated that GDNF, as well as SP and other more widely investigated messengers, undergoes activity-dependent release from nPAFs.

To establish whether or not GDNF was released at a sufficient concentration to elicit a local neuronal response in $\mathrm{SDH}$, we have used an anti-pERK1/2 antibody to evaluate the level of ERK1/2 phosphorylation as an early marker of neuronal activation (Ji et al., 1999). In these experiments (Fig. 9E,F), the increase of pERK1/2-IR that follows capsaicin stimulation was further incremented ( $p=0.027$, Kruskal-Wallis test) when GDNF released by 

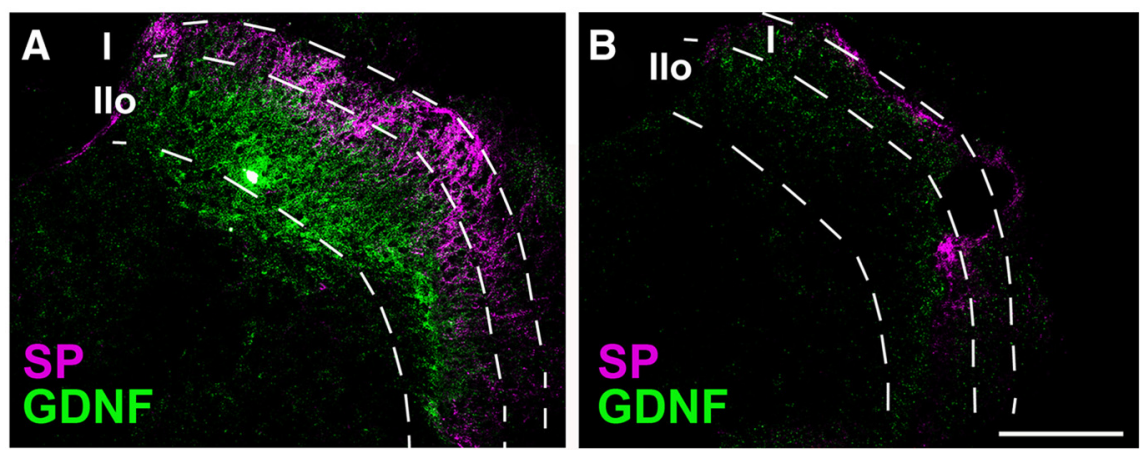

C

\section{D}

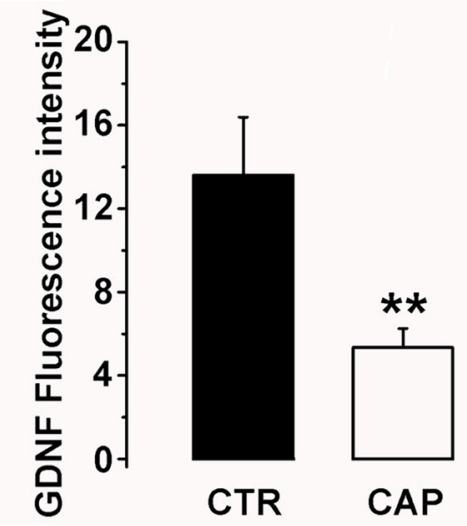

E

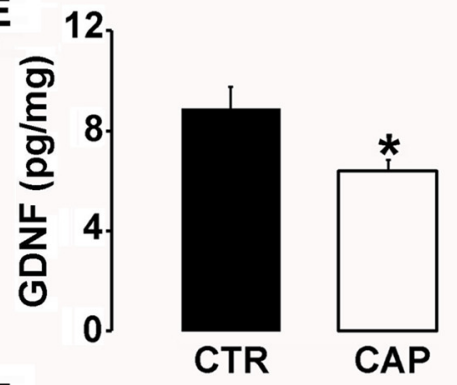

$\mathbf{F}$

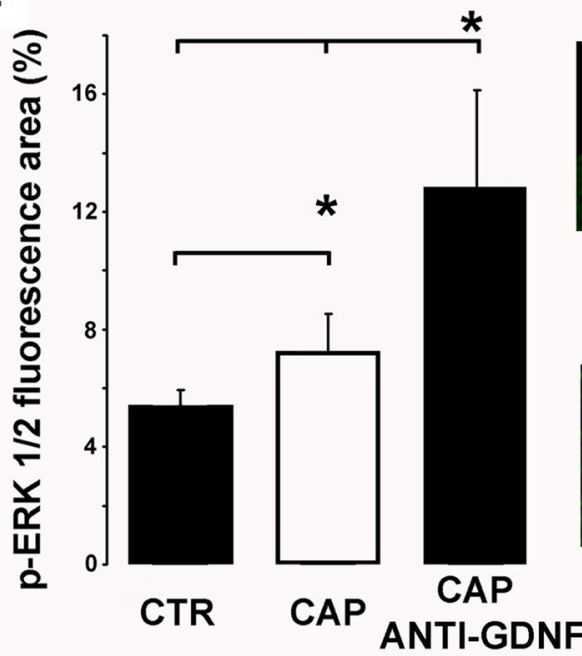

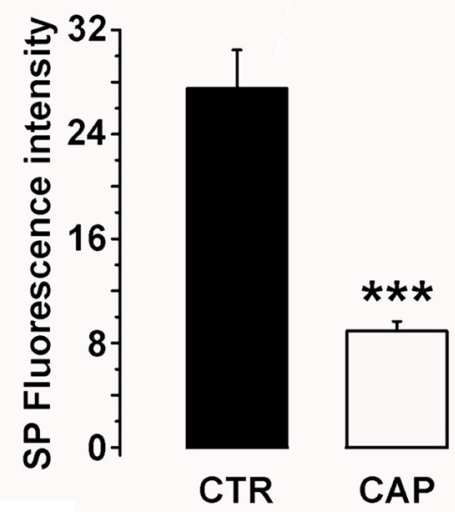

G
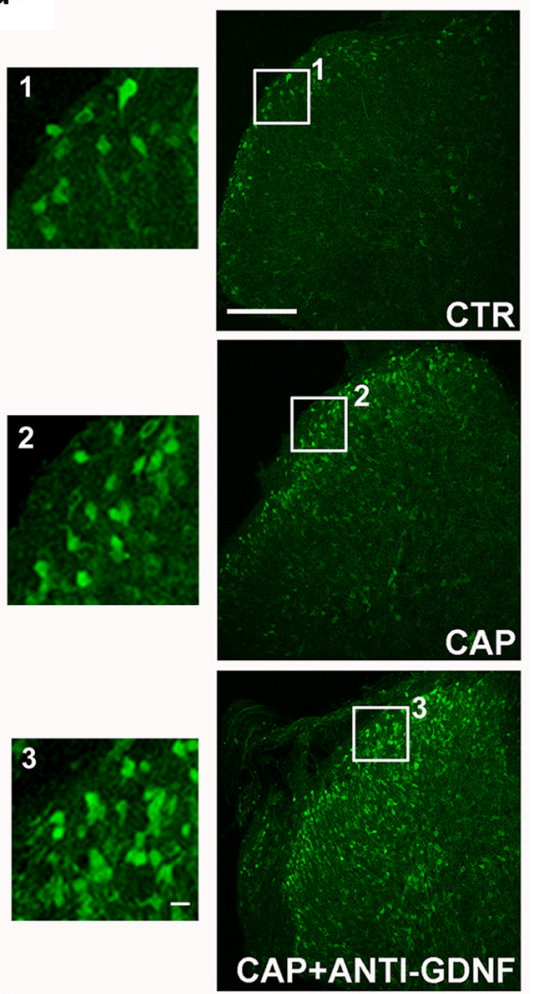

Figure 9. Release of GDNF from nPAFs and activation of SDH neurons in a slice preparation. Compared with controls $(\boldsymbol{A})$, the incubation of acute spinal cord slices with capsaicin $(\boldsymbol{B})$ causes a depletion of GDNF and SP-IRs in fibers of SDH. Histograms in $\boldsymbol{C}$ and D show the reduction of GDNF (C; control: $13.6 \pm 2.8, n=34$ sections; capsaicin: $5.3 \pm 0.9, n=34$ sections; $\left.{ }^{* *} p<0.01\right)$ and SP fluorescence intensities ( $\boldsymbol{D}$; control: $27.5 \pm 8.9, n=34$ sections; capsaicin: $8.9 \pm 0.7, n=34$ sections; $\left.{ }^{* * *} p<0.001\right)$ after capsaicin. $\boldsymbol{E}$, Depletion of GDNF content in slices subjected to capsaicin challenge after ELISA. The GDNF content measured in control and capsaicin-treated slices drops down from $8.9 \pm 0.9$ (control) to $6.4 \pm 0.5 \mathrm{pg} / \mathrm{mg}$ total protein (capsaicin; $n=4$ mice, ${ }^{*} p=$ 0.012). $\boldsymbol{F}$, Histogram showing the increase of p-ERK1/2 fluorescence area following capsaicin and in the presence of the anti-GDNF

nPAFs was inactivated by a neutralizing antibody. Conversely, the application of the anti-GDNF antibody alone, in the absence of an inflammatory-like stimulus that released the growth factor from nPAFs, did not significantly alter pERK $1 / 2$ expression $(5.3 \pm 0.8 \%$ of SDH area in control, $6.8 \pm 1.5 \%$ of SDH area with anti-GDNF; $n=4 ; p=0.49)$. As an interpretation of these findings it seems reasonable to conclude that whereas levels of GDNF under resting conditions are ineffective in altering basal neuronal activity, a response becomes well measurable after capsaicin. It is noteworthy that when slices were challenged with capsaicin + anti-GDNF antibody, the pERK1/2 response was mainly, but not only, evident in $\mathrm{SDH}$. We have previously demonstrated that capsaicin alone specifically increases pERK1/2 and Fos in laminae I-II (Ferrini et al., 2014). As the effect of antiGDNF antibody on capsaicin-induced ERK1/2 phosphorylation was measured in $\mathrm{SDH}$, where GDNF-expressing nPAFs terminate, it cannot be excluded that feedforward excitation might also spread to deep DH neurons via polysynaptic connections.

Bath-applied GDNF binds to GFR $\alpha 1$ and reduces the $\mathrm{Ca}^{2+}$ response of $\mathrm{SDH}$ neurons in a spinal cord slice preparation

Similarly to what occurs in vivo under acute inflammatory conditions, after capsaicin in vitro TRPV1-expressing PAFs release a variety of fast- and slow-acting transmitters/modulators. They all may be directly and/or indirectly involved in the response of SDH neurons recorded by imaging $\left[\mathrm{Ca}^{2+}\right]_{\mathrm{i}}$ at the confocal microscope (Merighi, 2002). In a first set of experiments (Fig. 10A-C), capsaicin, as expected, per se induced a sharp rise of $\left[\mathrm{Ca}^{2+}\right]_{\mathrm{i}}$ in the majority of SDH neurons. However, when GDNF (100 ng/ml) and capsaicin were coapplied, a significant reduction $(\sim 30 \%)$ in the capsaicin response was observed by measuring AUC (capsaicin: $49.1 \pm 6.0, n=76$ cells; capsaicin + GDNF: $33.1 \pm 3.8, n=60$ cells; $t$ test, $p=$ 0.035; Fig. $10 D, E)$. As a specificity control for the effect of GDNF, we pretreated slices with PI-PLC (1 U/ml). PI-PLC

neutralizing antibody (control: $5.4 \pm 0.5 \%$, capsaicin: $7.2 \pm$ $1.3 \%$, capsaicin + anti-GDNF: $12.8 \pm 3.3 \% ; n=5$ mice, $\left.{ }^{*} p<0.05\right)$. G, $p$-ERK1/2-IR in slices subjected to different experimental challenges and representative inserts at higher magnification (1, 2, and 3). CTR, control; (AP, capsaicin. Scale bars: $200 \mu \mathrm{m}$ 
cleaves the glycosylphosphatidylinositol anchor, which binds GFR $\alpha 1$ to the outer surface of the cell membrane, thus promoting the release of GFR $\alpha 1$ receptor from its anchorage point (Nicole et al., 2001). After pre-incubation with PI-PLC, the capsaicin response of SDH neurons in the presence of GDNF was higher than in paired slices without PI-PLC ( $t$ test, $p=$ 0.049; Fig. $10 F, G$ ), and undistinguishable from the response after capsaicin alone (Fig. 10F, dashed line).

Bath-applied GDNF reduces the capsaicin-induced presynaptic release of glutamate from nPAFs in a spinal cord slice preparation

As the GDNF receptor complex does not directly affect $\mathrm{Ca}^{2+}$ channels at the cell membrane and/or intracellular stores (Airaksinen and Saarma, 2002) and we demonstrated here it is mainly expressed in nPAFS, we devised a series of patchclamp experiments to address whether the GDNF affected SDH neurons via a presynaptic mechanism. As previously shown (Yang et al., 1998; Ferrini et al., 2010; Bencivinni et al., 2011), application of capsaicin to spinal cord slices induces a massive release of glutamate from nPAFs, which, in turn, produces a strong increase of mEPSC frequency in SDH neurons without affecting the synaptic current amplitude (Fig. $11 A-D)$. In the presence of capsaicin, mEPSC frequency shifted from $0.3 \pm 0.1$ to $10.0 \pm 2.5 \mathrm{~Hz}(n=10$; Wilcoxon test, $p=0.005$; Fig. $11 C$ ), with no change in amplitude $(14.4 \pm 2.1 \mathrm{pA}$ in control and $16.2 \pm 2.6 \mathrm{pA}$ in the presence of capsaicin; $n=10$; Wilcoxon test, $p=$ 0.285; Fig. $11 D$ ). When capsaicin was applied together with GDNF (100 nM), the frequency increase was still significant but smaller $(0.4 \pm 0.1$ to $3.4 \pm 10.3 \mathrm{~Hz} ; n=9$; Wilcoxon test, $p=0.008$; Fig. $11 C$ ), while amplitude did not change $(9.6 \pm 1.2 \mathrm{pA}$ in control and $9.4 \pm 0.7 \mathrm{pA}$ in the presence of capsaicin; $n=9$; Wilcoxon test, $p=$ 0.859; Fig. 11D). Frequency increase induced by capsaicin alone was $58 \pm 17$ times the control $(n=10)$, whereas in the presence of GDNF it was only $20 \pm 12$ times the control ( $n=9$; Mann-Whitney test, $p=0.013$; Fig. $11 E$ ). To test the specificity of the GDNF effect we pretreated slices with PI-PLC (1 U/ml, $30 \mathrm{~min})$. PI-PLC treatment did not significantly alter mEPSC frequency and amplitude (Mann-Whitney test $p=0.638, n=19$ and $p=0.070, n=18$, respectively) and capsaicin still induced a significant increase of mEPSC frequency, both alone (from $1.2 \pm 0.5$ to $12.2 \pm 3.4 \mathrm{~Hz} n=9$;

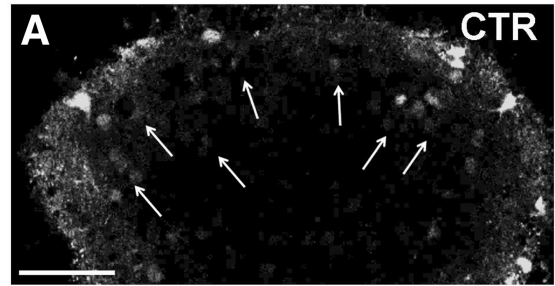

B
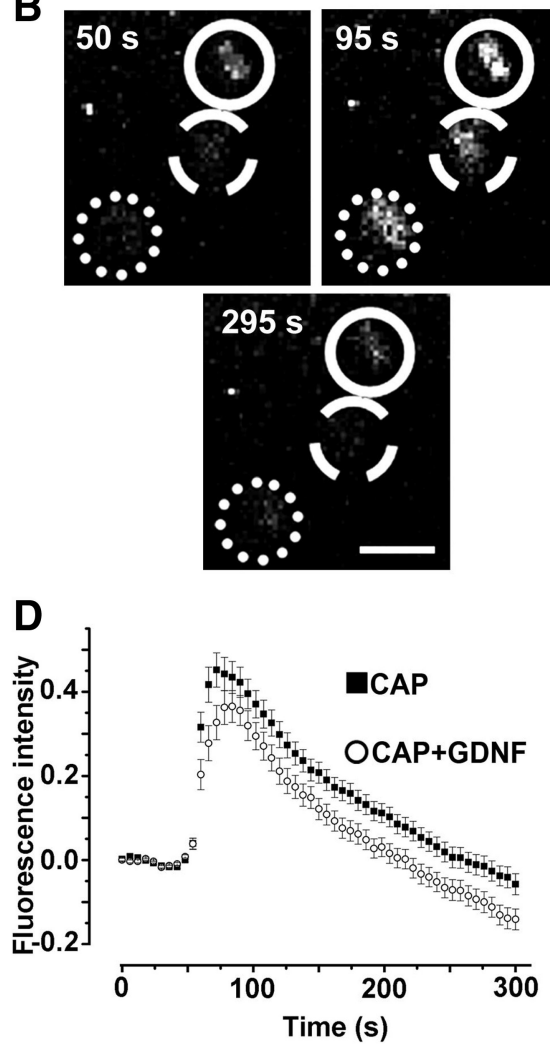

$\mathbf{F}$

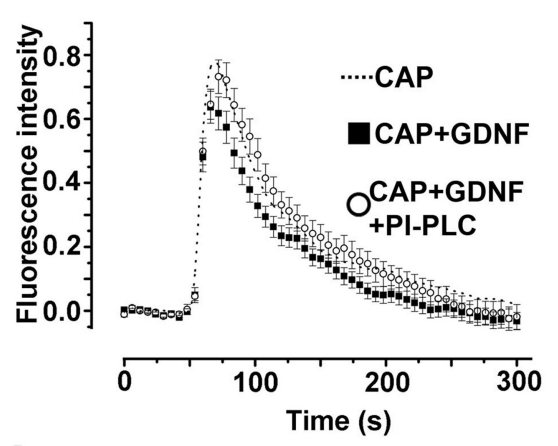

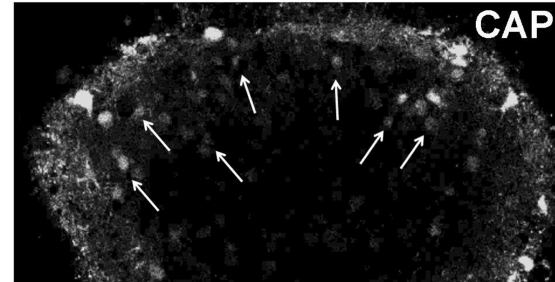

C

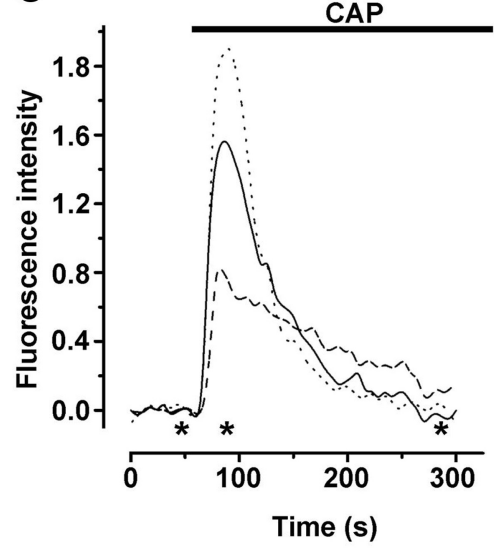

E

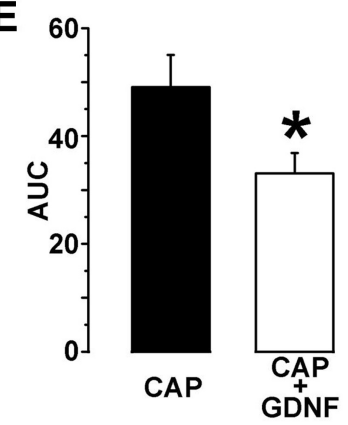

G

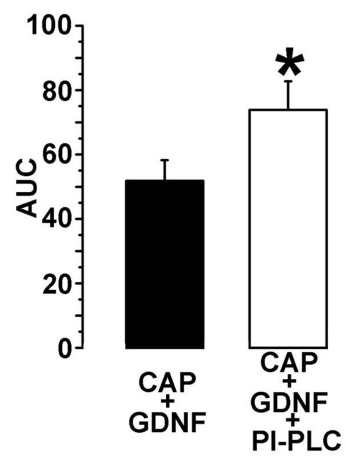

Figure 10. Bath-applied GDNF binds to GFR $\alpha 1$ and reduces the $\mathrm{Ca}^{2+}$ response of SDH neurons in a spinal cord slice preparation. $A$, Oregon Green-loaded cells before (left) and after (right) capsaicin challenge in a slice preparation. Arrows indicate a sample of capsaicin-responsive neurons. $\boldsymbol{B}, \boldsymbol{C}$, Representative images of the $\mathrm{Ca}^{2+}$ responses of three SDH neurons (solid, dashed, and dotted circles in $\boldsymbol{B}$; lines in $\boldsymbol{C}$ loaded with Oregon Green during capsaicin stimulation ( $2 \mu \mathrm{m}$ to $5 \mathrm{~min}$ ). The graph in $($ shows the time course of fluorescence intensity in each of the three cells (solid, dashed, and dotted lines). Asterisks correspond to the time points at which images in $\boldsymbol{B}$ were sampled. $\boldsymbol{D}$, Time course of mean fluorescence intensity in individual neurons during capsaicin stimulation with ( $n=60$; circles) or without ( $n=76$; squares) GDNF. E, AUC (arbitrary units) of capsaicin responses with (33.1 \pm 3.8 ; white bar) or without $(49.1 \pm 6.0$; black bar; $p<0.05)$ GDNF. $F$, Capsaicin-induced $\mathrm{Ca}^{2+}$ response in individual neurons in the presence of GDNF after pre-incubation with ( $n=61$; circles) or without ( $n=58$; squares) PI-PLC. The dotted line indicates the fluorescence intensity of parallel experiments performed with capsaicin alone $(n=71) . \mathbf{G}, \mathrm{AUC}$ (arbitrary units) of the capsaicin responses in the presence of GDNF after pre-incubation with (73.9 \pm 8.9 ; white bar) or without $(51.9 \pm 6.4$; black bar; $p<0.05)$ PI-PLC. Scale bars: $\boldsymbol{A}, 70 \mu \mathrm{m} ; \boldsymbol{B}, 30 \mu \mathrm{m}$. CAP, capsaicin. 
A

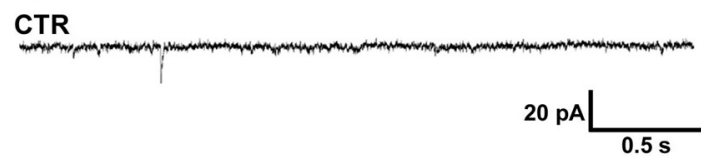

B CTR

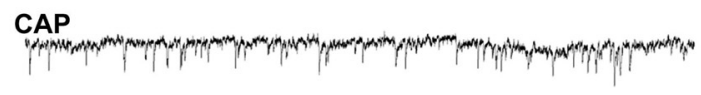

CAP + GDNF

C

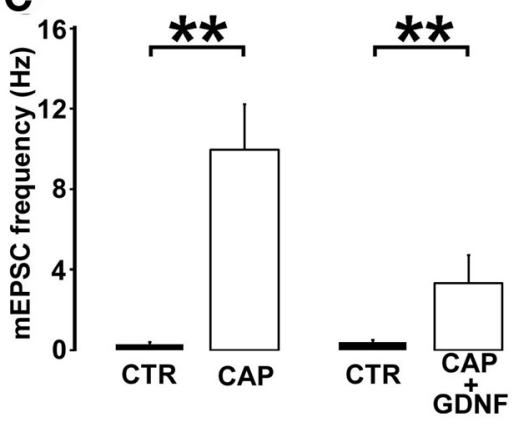

D

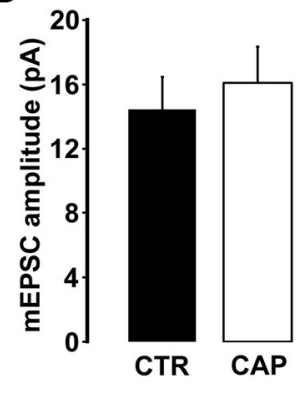

E

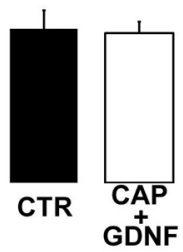

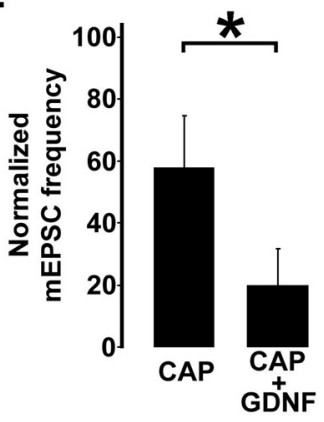

F

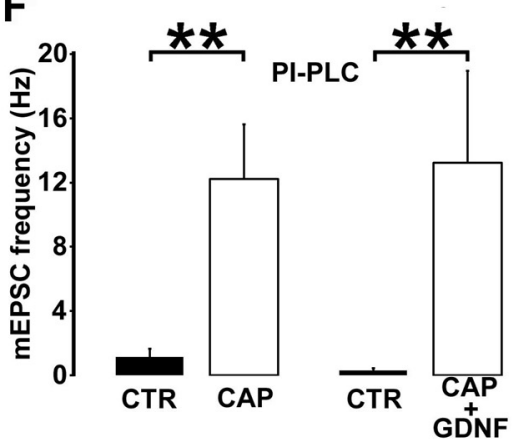

G

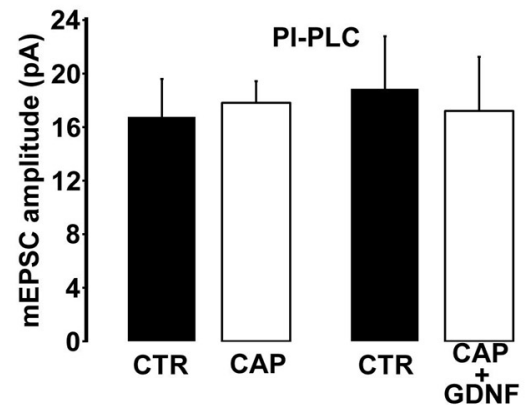

H

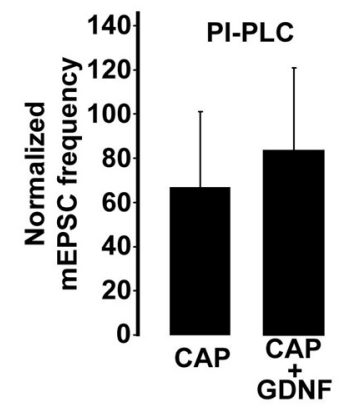

Figure 11. Bath-applied GDNF reduces the presynaptic release of glutamate from nPAFs in a slice preparation. $\boldsymbol{A}, \boldsymbol{B}$, Representative traces showing the effect of capsaicin ( $2 \mu \mathrm{m}, 5 \mathrm{~min})$ alone $(\boldsymbol{A})$ or in the presence of GDNF $(100 \mathrm{ng}, \boldsymbol{B})$ on mEPSCS in SDH neurons. $\boldsymbol{C}$, Pooled data showing the effect of capsaicin on mEPSC frequency alone (from $0.3 \pm 0.1$ to $10.0 \pm 2.5 \mathrm{~Hz} ; n=10 ; \mathrm{Wilcoxon}$ test, $p=0.005$ ) or in the presence of GDNF (from $0.4 \pm 0.1$ to $3.4 \pm 1.3 \mathrm{~Hz} ; n=9$; Wilcoxon test, $p=0.008$ ). D, Pooled data showing the lack of effect of capsaicin on mEPSC amplitude alone (14.4 \pm $2.1 \mathrm{pA}$, control; $16.2 \pm 2.6 \mathrm{pA}$, capsaicin; $n=10$; Wilcoxon test, $p=0.285)$ or in the presence of $\operatorname{GDNF}(9.6 \pm 1.2 \mathrm{pA}$, control; $9.4 \pm 0.7 \mathrm{pA}$, capsaicin; $n=9 ;$ Wilcoxon test, $p=0.859)$. $\boldsymbol{E}$, Histogram comparing the capsaicin-induced mEPSC frequency increase (normalized to control) in capsaicin alone (58 \pm 17 times control; $n=10)$ and in capsaicin + GDNF ( $20 \pm 12$ times control; $n=9$; Mann-Whitney test, $p=0.013$ ). $F$, Pooled data showing the effect of capsaicin on mEPSC frequency alone (from $1.2 \pm 0.5$ to $12.2 \pm 3.4 \mathrm{~Hz} n=9$; Wilcoxon test, $p=0.008$ ) or in the presence of GDNF (from $0.3 \pm 0.1$ to $13.2 \pm 5.7 \mathrm{~Hz} n=9$; Wilcoxon test, $p=0.008$ ) after PI-PLC treatment. G, Pooled data showing the lack of effect of capsaicin on mEPSC amplitude alone (16.8 \pm 2.8 $\mathrm{pA}$, control; $17.8 \pm 1.6 \mathrm{pA}$, capsaicin; $n=9$; Wilcoxon test, $p=0.594)$ or in the presence of GDNF (18.9 $\pm 3.9 \mathrm{pA}$, control; $17.2 \pm 4.0 \mathrm{pA}$, capsaicin; $n=9$; Wilcoxon test, $p=0.314)$ after PI-PLC treatment. $\boldsymbol{H}$, Histogram comparing the capsaicin-induced mEPSC frequency increase (normalized to control) in capsaicin alone (67 \pm 34 times control, $n=9)$ and in the presence of GDNF ( $83 \pm$ 38 times control, $n=9$; Mann-Whitney test, $p=0.796)$ after PI-PLC treatment. CTR, control; CAP, capsaicin.

Wilcoxon test, $p=0.008$; Fig. $11 F)$ and in the presence of GDNF (from $0.3 \pm 0.1$ to $13.2 \pm 5.7 \mathrm{~Hz} n=9$; Wilcoxon test, $p=0.008$; Fig. $11 F$ ), with no change in amplitude (Fig. $11 G$ ). However, in this case no significant differences were observed between the effect of capsaicin alone and capsaicin + GDNF (mEPSC frequency increase was as follows: $67 \pm 34$ times the control, $n=9$, capsaicin alone; $83 \pm 38$ times the control, $n=9$ capsaicin + GDNF; Mann-Whitney test, $p=0.796$; Fig. $11 H$ ).

\section{Discussion}

Here we have provided exhaustive immunocytochemical data on the distribution of GDNF and its receptor complex in the somatosensory system and evidence for a role of the growth factor in the control of nPAF transmission to SDH neurons in mouse.
Immunocytochemical distribution of GDNF/GFR $\alpha 1$-RET

We showed that GDNF is normally expressed by a specific subpopulation of peptidergic CGRP/SST ${ }_{28}$ nociceptors and by their $\mathrm{C}$ terminals at GIb in lamina II, whereas the GFR $\alpha 1-\mathrm{RET}$ receptor complex was detected in nonpeptidergic IB4+ nociceptors and their $\mathrm{C}$ terminals at GIa. Information obtained here in mouse should be similar for rat, and also in consideration of our previous work on the comparative expression of BDNF/TrkB in the two species (Salio et al., 2007; Merighi et al., 2008). However, as mentioned in the Results, sound interspecies comparisons are difficult, primarily because IB4 binding may not be sufficient for a clear distinction between the peptidergic and nonpeptidergic nociceptor subclasses in rat (Price and Flores, 2007). Irrespective of (putative) interspecies differences, localization data are sup- 


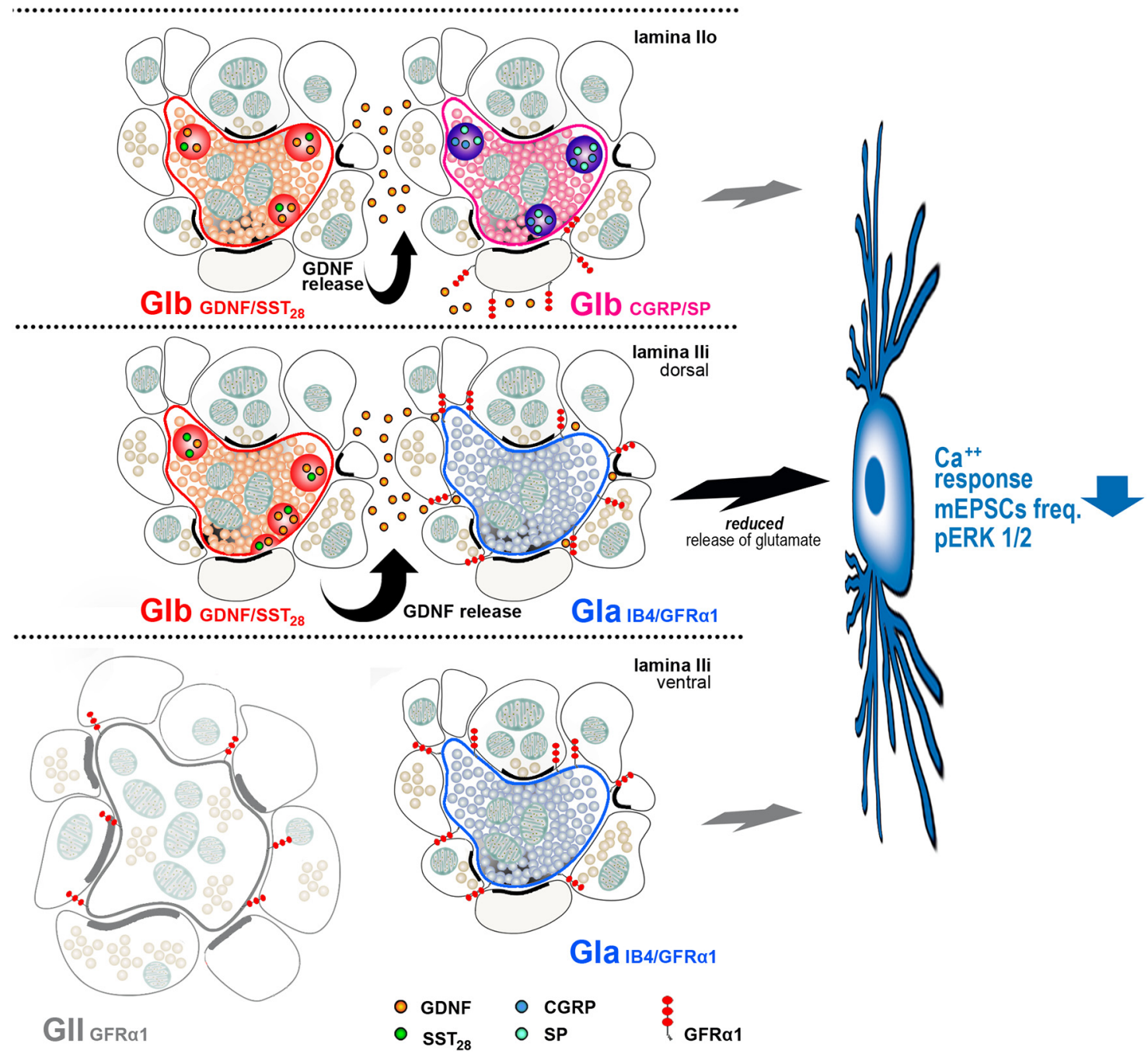

Figure 12. Schematic drawing illustrating the GDNF-modulated cross talk between nPAFs at glomeruli and the effect on activity of lamina II neurons. Glomeruli are represented in relation to their sublaminar localization. Capsaicin-responsive C-terminal endings of nPAFs in type I glomeruli (GI) are color coded on the basis of their growth factor/peptide content. Glutamate-containing agranular vesicles are represented using the same colors. For simplicity, only GFR $\alpha 1$ receptors at glomeruli are represented. Modulation of the activity of lamina II neurons by GDNF (large curved arrow) mainly occurs in lamina II $\mathrm{d}$, which contains a higher incidence of type I glomeruli (Ribeiro-da-Silva and De Koninck, 2008) and 50\% of the GDNF-IR and IB4+ profiles (Fig. 4D,E). Such an arrangement is therefore consistent with a presynaptic inhibition of the activity of lamina II neurons (straight black arrow). It is also possible that GDNF released at GI-containing SST 28 binds to GFR $\alpha 1$-IR dendrites engaged in CGRP/SP-IR GIb in lamina $I_{0}$ (small curved arrow). This is an additional circuit that may be indirectly responsible for the effects of GDNF on SDH neurons (small straight black arrow at reduced opacity). However, this type of interaction is very likely less efficacious in determining the response of lamina II neurons, as lamina II ${ }_{0}$ contains lower numbers of glomeruli than the more ventral sublaminae (Ribeiro-da-Silva and De Koninck, 2008 and Fig. 4D). Interactions with glomeruli in lamina Il $\mathrm{j}$ v that display GFR $\alpha 1$ in C terminals (Gla) or dendrites (GII) are more unlikely, as growth factors have limited capabilities of diffusion in the extracellular space before being inactivated (small, straight black arrow at reduced opacity). Nonetheless, it cannot be excluded that these interactions occur after a massive release of GDNF. Glb-containing GGP/SP also contains BDNF that can contribute to the excitatory drive of lamina II neurons (Merighi et al., 2008) but is not represented here for clarity.

portive for a transmitter role of GDNF in the somatosensory system.

Previous GDNF work was focused on the survival and neuroprotective effects of the growth factor in development or experimental injury (see Introduction). Our data, however, are not in conflict with this literature, as we detected a fraction of GDNF-IR DRG neurons that did not contain peptides and/or TRPV1, but this neurochemical pattern was not observed at terminal level in $\mathrm{SDH}$. Therefore, the GDNF contained in these neurons is unlikely to be involved in the regulation of the activity of nPAFs and may be subserving the more classical maintenance and trophic functions currently ascribed to growth factors.

\section{GDNF as a nociceptive modulator}

Our in vitro observations upon capsaicin depolarization of $\mathrm{nPAF}$ terminals showed that (1) endogenous GDNF is released from these terminals, (2) bath-applied GDNF attenuates capsaicin activation of SDH neurons, and (3) this type of inhibitory modulation is mediated via a presynaptic mechanism.

Altogether, they disclose a novel signaling pathway in SDH, by which the GDNF released from peptidergic nPAF terminals negatively modulates the activation of other subsets of nPAFs (Fig. 12).

Information is accumulating in support of a role for growth factors as modulators of synapses in the mature brain. In the somatosensory system, BDNF is recognized as a pain modulator (Pezet et al., 2002; Merighi et al., 2008). Intriguingly, its distribution and that of GDNF, as emerges from the present study, share important analogies, they both (1) are detected in small- to medium-sized DRG neurons giving rise to peptidergic nPAFs, (2) coexist with the main neuropeptides that have been implicated as modulators of pain (SP and $\mathrm{SST}_{28}$, respectively), and (3) are an- 
terogradely transported to the SDH (Zhou and Rush, 1996; Holstege et al., 1998; Ohta et al., 2001; Rind and von Bartheld, 2002; Salio et al., 2007). However, full understanding of the impact of these molecules on synaptic transmission is hampered by an intricate pharmacology. Neurotrophic factors, including GDNF, can bind different membrane receptors (Boucher and McMahon, 2001; Paratcha et al., 2003), the same receptors may differ in their membrane organization and/or phosphorylation state (RunebergRoos and Saarma, 2007) and, eventually, they may activate different downstream signaling pathways according to their subcellular localization (Paratcha et al., 2001; Richardson et al., 2006). Thus, it is not surprising that different studies have provided contrasting evidence as to the role of GDNF in nociceptive transmission and neuronal activity. Indeed, in dissociated DRG neurons GDNF was found to enhance capsaicin-evoked $\mathrm{Ca}^{2+}$ currents (Malin et al., 2006), while in vagal afferent neurons it caused a significant inhibition of the capsaicin-induced calcium influx (Nandigama et al., 2012). Similarly, intrathecal injection of GDNF has been reported to increase early gene expression in $\mathrm{DH}$ neurons (Jongen et al., 2005), suggesting a pronociceptive role (Fang et al., 2003). On the other hand, intrathecal GDNF has also been found to counteract SP hyperalgesic effects (Malcangio et al., 2000), and additional evidence supports its antinociceptive function in neuropathic pain models (Boucher et al., 2000; Dong et al., 2006; Sakai et al., 2008).

In the present study, we have provided an in-depth histological and structural analysis of the distribution of GDNF and its receptor complex in nociceptors and their synapses in lamina II, and shed more light on its modulatory role at these synapses using an established slice model of inflammatory pain that employs capsaicin as a tool to activate SDH neurons (Vergnano et al., 2008). Capsaicin is known for its ability to activate nPAFs peripherally and centrally (Carlton et al., 2004; Kawasaki et al., 2004; Bencivinni et al., 2011), and micromolar concentrations of the vanilloid applied to spinal cord slices specifically induce the release of glutamate, peptides, and neurotrophic factors from their C terminals (Ferrini et al., 2007, 2010; Merighi et al., 2008). $\mathrm{Ca}^{2+}$-imaging experiments demonstrated that bath-applied GDNF, acting through the GFR $\alpha 1$-RET receptor complex, reduces to $\sim 70 \%$ the overall capsaicin-induced activation of SDH neurons. This negative modulation on the capsaicin excitatory drive was shown to be grounded on a reduced glutamate release from nPAF terminals, as demonstrated by the lower frequency of mEPSCs in the presence of GDNF. As we have also demonstrated that endogenous GDNF was released from nPAFs in our slice model of inflammation, and that scavenging GDNF increased the capsaicin-induced activation of SDH neurons, a similar mechanism potentially acts under inflammatory conditions in vivo. In considering this perspective, it is worth noting here that clinical evidence is continuously accumulating in support of a role for molecules of the GDNF family in the treatment of certain types of pain (Bartolini et al., 2011).

There are several limitations to investigating in more depth the intracellular mechanism underlying the activity of GDNF in vitro by our current approach. Nonetheless, we can better unravel the inhibition of SDH neurons. Two main populations of peptidergic nPAFs are distinguished in lamina II of the $\mathrm{DH}$ and the one expressing $\mathrm{SST}_{28}+$ CGRP accounts for approximately one-third of the total in rat (Ribeiro-da-Silva, 2004). In this respect, we show here-also after ultrastructural quantitative estimation-that GDNF was specifically restricted to these fibers. The GDNF receptor complex had instead a more heterogeneous distribution (Fig. $4 F$ ), as, in juvenile mice, $28 \%$ of IR profiles were the $\mathrm{C}$ terminals of non-nociceptive A fibers in GII and 15\% were dendrites of unknown origin. The remaining profiles, which were quantitatively remarkably stable in postnatal and juvenile animals, were the $\mathrm{C}$ terminals of the nonpeptidergic IB4 + nPAFs in GIa. The latter also expressed the SST receptor SSTR2a (Bencivinni et al., 2011). The emerging picture not only was that the nonpeptidergic IB4+/GFR $\alpha 1$-RET/SSTR2a nPAFs were "specular" functional targets for their peptidergic CGRP/SST ${ }_{28} / \mathrm{GDNF}$ counterparts, but also that any signaling interaction between the two was likely to specifically occur in $\mathrm{LII}_{\mathrm{i}} \mathrm{d}$, which, at the same time, contains approximately half of the GDNF- and GFR $\alpha 1$-IR profiles (Fig. 4F) and a mix of GIa and GIb. This finding is very important because (1) a close spatial proximity is mandatory for secreted GDNF (and growth factors) to act at synapses before being inactivated by tissue proteases (Airaksinen and Saarma, 2002) and (2) $\mathrm{II}_{\mathrm{i}} \mathrm{d}$ is specifically populated by $\mathrm{C}$ fibers that are activated in the second phase of pain (Ribeiro-da-Silva and De Koninck, 2008). Thus, the most parsimonious circuit underlying the GDNF effects on SDH neurons in vivo can be envisaged in terms of a cross talk between GDNF-IR peptidergic and IB4+ nonpeptidergic nociceptors of the $\mathrm{C}$ type (Fig. 12).

Recently, McCoy et al. (2013) have functionally demonstrated a similar type of cross talk by showing that the ablation of heatsensitive CGRP nociceptors potentiates the transmission of cold information to SDH neurons. Our present data provide a sound structural and functional support to propose GDNF as a key signaling molecule in this type of communication. The debate as to the site(s) where specific pain modalities are encoded remains open. However, at least in the case of thermosensation the exchange of information between peptidergic and nonpeptidergic primary sensory neurons appears fundamental for stimulus discrimination (Cavanaugh et al., 2009; Pogorzala et al., 2013).

In conclusion, our data unravel the role of GDNF as a novel synaptic messenger for the processing of nociceptive information in SDH. As different pain modalities seem to be specifically associated to peptidergic versus nonpeptidergic subtypes of nociceptors (Cavanaugh et al., 2009), the GDNF signal may have important implications in the qualitative discrimination of nociceptive stimuli. Interestingly, both peptidergic and nonpeptidergic nPAFs project onto virtually all the neuronal types so far described in lamina II (Ferrini et al., 2007; Wang and Zylka, 2009). It is therefore possible that the main site for modality discrimination is indeed in nociceptors, rather than in spinal or supraspinal sites. In this respect, a peptidergic to nonpeptidergic C-fiber communication pathway mediated by GDNF may preserve the specificity of the nociceptive input under normal conditions, and exert a protective inhibition during the central responses to inflammatory pain.

\section{References}

Adler JE (1998) Age-dependent differential regulation of sensory neuropeptides by glial cell line-derived neurotrophic factor. J Neurochem 71:170177. Medline

Airaksinen MS, Saarma M (2002) The GDNF family: signalling, biological functions and therapeutic value. Nat Rev Neurosci 3:383-394. CrossRef Medline

Altman LG, Schneider BG, Papermaster DS (1984) Rapid embedding of tissues in Lowicryl K4M for immunoelectron microscopy. J Histochem Cytochem 32:1217-1223. CrossRef Medline

Bailey AL, Ribeiro-da-Silva A (2006) Transient loss of terminals from nonpeptidergic nociceptive fibers in the substantia gelatinosa of spinal cord following chronic constriction injury of the sciatic nerve. Neuroscience 138:675-690. CrossRef Medline

Bartolini A, Di Cesare Mannelli L, Ghelardini C (2011) Analgesic and anti- 
neuropathic drugs acting through central cholinergic mechanisms. Recent Pat CNS Drug Discov 6:119-140. CrossRef Medline

Battaglia G, Molinaro G, Riozzi B, Storto M, Busceti CL, Spinsanti P, Bucci D, Di Liberto V, Mudò G, Corti C, Corsi M, Nicoletti F, Belluardo N, Bruno $\mathrm{V}$ (2009) Activation of mGlu3 receptors stimulates the production of GDNF in striatal neurons. PLoS One 4:e6591. CrossRef Medline

Bencivinni I, Ferrini F, Salio C, Beltramo M, Merighi A (2011) The somatostatin analogue octreotide inhibits capsaicin-mediated activation of nociceptive primary afferent fibres in spinal cord lamina II (substantia gelatinosa). Eur J Pain 15:591-599. CrossRef Medline

Bennett DL, Michael GJ, Ramachandran N, Munson JB, Averill S, Yan Q, McMahon SB, Priestley JV (1998) A distinct subgroup of small DRG cells express GDNF receptor components and GDNF is protective for these neurons after nerve injury. J Neurosci 18:3059-3072. Medline

Bennett DL, Boucher TJ, Armanini MP, Poulsen KT, Michael GJ, Priestley JV, Phillips HS, McMahon SB, Shelton DL (2000) The glial cell line-derived neurotrophic factor family receptor components are differentially regulated within sensory neurons after nerve injury. J Neurosci 20:427-437. Medline

Boucher TJ, McMahon SB (2001) Neurotrophic factors and neuropathic pain. Curr Opin Pharmacol 1:66-72. CrossRef Medline

Boucher TJ, Okuse K, Bennett DL, Munson JB, Wood JN, McMahon SB (2000) Potent analgesic effects of GDNF in neuropathic pain states. Science 290:124-127. CrossRef Medline

Bourane S, Garces A, Venteo S, Pattyn A, Hubert T, Fichard A, Puech S, Boukhaddaoui H, Baudet C, Takahashi S, Valmier J, Carroll P (2009) Low-threshold mechanoreceptor subtypes selectively express MafA and are specified by Ret signaling. Neuron 64:857-870. CrossRef Medline

Carlton SM, Zhou S, Du J, Hargett GL, Ji G, Coggeshall RE (2004) Somatostatin modulates the transient receptor potential vanilloid 1 (TRPV1) ion channel. Pain 110:616-627. CrossRef Medline

Carmillo P, Dagø L, Day ES, Worley DS, Rossomando A, Walus L, Orozco O, Buckley C, Miller S, Tse A, Cate RL, Rosenblad C, Sah DW, Grønborg M, Whitty A (2005) Glial cell line-derived neurotrophic factor (GDNF) receptor alpha-1 (GFR alpha 1) is highly selective for GDNF versus artemin. Biochemistry 44:2545-2554. CrossRef Medline

Cavanaugh DJ, Lee H, Lo L, Shields SD, Zylka MJ, Basbaum AI, Anderson DJ (2009) Distinct subsets of unmyelinated primary sensory fibers mediate behavioral responses to noxious thermal and mechanical stimuli. Proc Natl Acad Sci U S A 106:9075-9080. CrossRef Medline

Cesa R, Morando L, Strata P (2003) Glutamate receptor delta2 subunit in activity-dependent heterologous synaptic competition. J Neurosci 23: 2363-2370. Medline

Charbel Issa P, Lever IJ, Michael GJ, Bradbury EJ, Malcangio M (2001) Intrathecally delivered glial cell line-derived neurotrophic factor produces electrically evoked release of somatostatin in the dorsal horn of the spinal cord. J Neurochem 78:221-229. CrossRef Medline

Dong ZQ, Wang YQ, Ma F, Xie H, Wu GC (2006) Down-regulation of GFRalpha-1 expression by antisense oligodeoxynucleotide aggravates thermal hyperalgesia in a rat model of neuropathic pain. Neuropharmacology 50:393-403. CrossRef Medline

Durbec P, Marcos-Gutierrez CV, Kilkenny C, Grigoriou M, Wartiowaara K, Suvanto P, Smith D, Ponder B, Costantini F, Saarma M (1996) GDNF signalling through the Ret receptor tyrosine kinase. Nature 381:789-793. CrossRef Medline

Fang M, Wang Y, He QH, Sun YX, Deng LB, Wang XM, Han JS (2003) Glial cell line-derived neurotrophic factor contributes to delayed inflammatory hyperalgesia in adjuvant rat pain model. Neuroscience 117:503-512. CrossRef Medline

Ferrini F, Salio C, Vergnano AM, Merighi A (2007) Vanilloid receptor-1 (TRPV1)-dependent activation of inhibitory neurotransmission in spinal substantia gelatinosa neurons of mouse. Pain 129:195-209. CrossRef Medline

Ferrini F, Salio C, Lossi L, Gambino G, Merighi A (2010) Modulation of inhibitory neurotransmission by the vanilloid receptor type 1 (TRPV1) in organotypically cultured mouse substantia gelatinosa neurons. Pain 150: 128-140. CrossRef Medline

Ferrini F, Russo A, Salio C (2014) Fos and pERK immunoreactivity in spinal cord slices: comparative analysis of in vitro models for testing putative antinociceptive molecules. Ann Anat 196:217-223. CrossRef Medline

Fitzgerald M (2005) The development of nociceptive circuits. Nat Rev Neurosci 6:507-520. CrossRef Medline
Forrest SL, Keast JR (2008) Expression of receptors for glial cell line-derived neurotrophic factor family ligands in sacral spinal cord reveals separate targets of pelvic afferent fibers. J Comp Neurol 506:989-1002. CrossRef Medline

Holstege JC, Jongen JL, Kennis JH, van Rooyen-Boot AA, Vecht CJ (1998) Immunocytochemical localization of GDNF in primary afferents of the lumbar dorsal horn. Neuroreport 9:2893-2897. CrossRef Medline

Hu J, Huang T, Li T, Guo Z, Cheng L (2012) c-Maf is required for the development of dorsal horn laminae III/IV neurons and mechanoreceptive DRG axon projections. J Neurosci 32:5362-5373. CrossRef Medline

Ji RR, Baba H, Brenner GJ, Woolf CJ (1999) Nociceptive-specific activation of ERK in spinal neurons contributes to pain hypersensitivity. Nat Neurosci 2:1114-1119. CrossRef Medline

Jongen JL, Haasdijk ED, Sabel-Goedknegt H, van der Burg J, Vecht ChJ, Holstege JC (2005) Intrathecal injection of GDNF and BDNF induces immediate early gene expression in rat spinal dorsal horn. Exp Neurol 194:255-266. CrossRef Medline

Josephson A, Widenfalk J, Trifunovski A, Widmer HR, Olson L, Spenger C (2001) GDNF and NGF family members and receptors in human fetal and adult spinal cord and dorsal root ganglia. J Comp Neurol 440:204217. CrossRef Medline

Kawasaki Y, Kohno T, Zhuang ZY, Brenner GJ, Wang H, Van Der Meer C, Befort K, Woolf CJ, Ji RR (2004) Ionotropic and metabotropic receptors, protein kinase A, protein kinase $\mathrm{C}$ and Src contribute to C-fiberinduced ERK activation and c-AMP response element-binding protein phosphorylation in dorsal horn neurons, leading to central sensitization. J Neurosci 24:8310-8321. CrossRef Medline

Keast JR, Forrest SL, Osborne PB (2010) Sciatic nerve injury in adult rats causes distinct changes in the central projections of sensory neurons expressing different glial cell line-derived neurotrophic factor family receptors. J Comp Neurol 518:3024-3045. CrossRef Medline

Kirshenbaum GS, Clapcote SJ, Duffy S, Burgess CR, Petersen J, Jarowek KJ, Yücel YH, Cortez MA, Snead OC 3rd, Vilsen B, Peever JH, Ralph MR, Roder JC (2011) Mania-like behavior induced by genetic dysfunction of the neuron-specific $\mathrm{Na}+, \mathrm{K}+$-ATPase alpha3 sodium pump. Proc Natl Acad Sci U S A 108:18144-18149. CrossRef Medline

Lonka-Nevalaita L, Lume M, Leppänen S, Jokitalo E, Peränen J, Saarma M (2010) Characterization of the intracellular localization, processing, and secretion of two glial cell line-derived neurotrophic factor splice isoforms. J Neurosci 30:11403-11413. CrossRef Medline

Malcangio M (2003) GDNF and somatostatin in sensory neurones. Curr Opin Pharmacol 3:41-45. CrossRef Medline

Malcangio M, Ramer MS, Boucher TJ, McMahon SB (2000) Intrathecally injected neurotrophins and the release of substance $\mathrm{P}$ from the rat isolated spinal cord. Eur J Neurosci 12:139-144. CrossRef Medline

Malcangio M, Getting SJ, Grist J, Cunningham JR, Bradbury EJ, Charbel Issa P, Lever IJ, Pezet S, Perretti M (2002) A novel control mechanism based on GDNF modulation of somatostatin release from sensory neurones. FASEB J 16:730-732. Medline

Malin SA, Molliver DC, Koerber HR, Cornuet P, Frye R, Albers KM, Davis BM (2006) Glial cell line-derived neurotrophic factor family members sensitize nociceptors in vitro and produce thermal hyperalgesia in vivo. J Neurosci 26:8588-8599. CrossRef Medline

Matheson CR, Carnahan J, Urich JL, Bocangel D, Zhang TJ, Yan Q (1997) Glial cell line-derived neurotrophic factor (GDNF) is a neurotrophic factor for sensory neurons: comparison with the effects of the neurotrophins. J Neurobiol 32:22-32. CrossRef Medline

McCoy ES, Taylor-Blake B, Street SE, Pribisko AL, Zheng J, Zylka MJ (2013) Peptidergic CGRP $\alpha$ primary sensory neurons encode heat and itch and tonically suppress sensitivity to cold. Neuron 78:138-151. CrossRef Medline

Merighi A (2002) Costorage and coexistence of neuropeptides in the mammalian CNS. Prog Neurobiol 66:161-190. CrossRef Medline

Merighi A, Polak JM (1993) Postembedding immunogold staining. In: Immunohistochemistry II (Cuello AC, ed), pp 229-264. New York: Wiley.

Merighi A, Polak JM, Fumagalli G, Theodosis DT (1989) Ultrastructural localization of neuropeptides and GABA in rat dorsal horn: a comparison of different immunogold labeling techniques. J Histochem Cytochem 37:529-540. CrossRef Medline

Merighi A, Polak JM, Theodosis DT (1991) Ultrastructural visualization of glutamate and aspartate immunoreactivities in the rat dorsal horn, with special reference to the co-localization of glutamate, substance $\mathrm{P}$ and 
calcitonin-gene related peptide. Neuroscience 40:67-80. CrossRef Medline

Merighi A, Salio C, Ghirri A, Lossi L, Ferrini F, Betelli C, Bardoni R (2008) BDNF as a pain modulator. Prog Neurobiol 85:297-317. CrossRef Medline

Molliver DC, Wright DE, Leitner ML, Parsadanian AS, Doster K, Wen D, Yan Q, Snider WD (1997) IB4-binding DRG neurons switch from NGF to GDNF dependence in early postnatal life. Neuron 19:849-861. CrossRef Medline

Nandigama R, Weske A, Wiegand S, Kummer W, Nassenstein C (2012) Mechanism of bronchopulmonary C-fiber hyperexcitability in allergic asthma: loss of TRPV1 inhibition by GDNF downregulation? Pneumologie 66-A210 Congress Abstract. CrossRef

Nicole O, Ali C, Docagne F, Plawinski L, MacKenzie ET, Vivien D, Buisson A (2001) Neuroprotection mediated by glial cell line-derived neurotrophic factor: involvement of a reduction of NMDA-induced calcium influx by the mitogen-activated protein kinase pathway. J Neurosci 21:3024-3033. Medline

Ohta K, Inokuchi T, Gen E, Chang J (2001) Ultrastructural study of anterograde transport of glial cell line-derived neurotrophic factor from dorsal root ganglion neurons of rats towards the nerve terminal. Cells Tissues Organs 169:410-421. CrossRef Medline

Paratcha G, Ledda F, Baars L, Coulpier M, Besset V, Anders J, Scott R, Ibáñez CF (2001) Released GFRalphal potentiates downstream signaling, neuronal survival and differentiation via a novel mechanism $\mathrm{f}$ recruitment of c-Ret to lipid rafts. Neuron 29:171-184. CrossRef Medline

Paratcha G, Ledda F, Ibáñez CF (2003) The neural cell adhesion molecule NCAM is an alternative signaling receptor for GDNF family ligands. Cell 113:867-879. CrossRef Medline

Park H, Poo MM (2013) Neurotrophin regulation of neural circuit development and function. Nat Rev Neurosci 14:7-23. CrossRef Medline

Pasti L, Volterra A, Pozzan T, Carmignoto G (1997) Intracellular calcium oscillations in astrocytes: a highly plastic, bidirectional form of communication between neurons and astrocytes in situ. J Neurosci 17:78177830. Medline

Peters A, Palay SL, Webster HD (1991) The fine structure of the nervous system: neurons and their supporting cells. New York: Oxford UP.

Pezet S, Malcangio M, McMahon SB (2002) BDNF: a neuromodulator in nociceptive pathways? Brain Res Brain Res Rev 40:240-249. CrossRef Medline

Pogorzala LA, Mishra SK, Hoon MA (2013) The cellular code for mammalian thermosensation. J Neurosci 33:5533-5541. CrossRef Medline

Price TJ, Flores CM (2007) Critical evaluation of the colocalization between calcitonin gene-related peptide, substance $\mathrm{P}$, transient receptor potential vanilloid subfamily type 1 immunoreactivities, and isolectin B4 binding in primary afferent neurons of the rat and mouse. J Pain 8:263-272. CrossRef Medline

Ramer MS, Priestley JV, McMahon SB (2000) Functional regeneration of sensory axons into the adult spinal cord. Nature 403:312-316. CrossRef Medline

Ribeiro-da-Silva A (2004) Substantia gelatinosa of the spinal cord. In: The rat nervous system (Paxinos G, ed), pp 129-148. San Diego: Elsevier Academic.

Ribeiro-da-Silva A, De Koninck Y (2008) Morphological and neurochemical organization of the spinal dorsal horn. In: The senses-a comprehensive ref- erence, Vol 5, Pain (Bushnell MC and Basbaum AI, Eds), pp 279-310. San Diego: Academic Press.

Richardson DS, Lai AZ, Mulligan LM (2006) RET ligand-induced internalization and its consequences for downstream signalling. Oncogene 25: 3206-3211. CrossRef Medline

Rind HB, von Bartheld CS (2002) Anterograde axonal transport of internalized GDNF in sensory and motor neurons. Neuroreport 13:659-664. CrossRef Medline

Runeberg-Roos P, Saarma M (2007) Neurotrophic factor receptor RET: structure, cell biology and inherited diseases. Ann Med 39:572-580. CrossRef Medline

Sah DW, Ossipov MH, Rossomando A, Silvian L, Porreca F (2005) New approaches for the treatment of pain: the GDNF family of neurotrophic growth factors. Curr Top Med Chem 5:577-583. Medline

Sakai A, Asada M, Seno N, Suzuki H (2008) Involvement of neural cell adhesion molecule signaling in glial cell line-derived neurotrophic factorinduced analgesia in a rat model of neuropathic pain. Pain 137:378-388. CrossRef Medline

Salio C, Lossi L, Ferrini F, Merighi A (2005) Ultrastructural evidence for a pre- and postsynaptic localization of full-length trkB receptors in substantia gelatinosa (lamina II) of rat and mouse spinal cord. Eur J Neurosci 22:1951-1966. CrossRef Medline

Salio C, Averill S, Priestley JV, Merighi A (2007) Costorage of BDNF and neuropeptides within individual dense-core vesicles in central and peripheral neurons. Dev Neurobiol 67:326-338. CrossRef Medline

Salio C, Lossi L, Merighi A (2011) Combined light and electron microscopic visualization of neuropeptides and their receptors in central neurons. In: Neuropeptides: methods and protocols. Vol 789, Methods in Molecular Biology (Merighi A, ed), pp 57-71. New York: Humana.

Schmutzler BS, Roy S, Hingtgen CM (2009) Glial cell line-derived neurotrophic factor family ligands enhance capsaicin-stimulated release of calcitonin gene-related peptide from sensory neurons. Neuroscience 161: 148-156. CrossRef Medline

Treanor JJ, Goodman L, de Sauvage F, Stone DM, Poulsen KT, Beck CD, Gray C, Armanini MP, Pollock RA, Hefti F, Phillips HS, Goddard A, Moore MW, Buj-Bello A, Davies AM, Asai N, Takahashi M, Vandlen R, Henderson CE, Rosenthal A (1996) Characterization of a multicomponent receptor for GDNF. Nature 382:80-83. CrossRef Medline

Vergnano AM, Ferrini F, Salio C, Lossi L, Baratta M, Merighi A (2008) The gastrointestinal hormone ghrelin modulates inhibitory neurotransmission in deep laminae of mouse spinal cord dorsal horn. Endocrinology 149:2306-2312. CrossRef Medline

Wang BL, Larsson LI (1985) Simultaneous demonstration of multiple antigens by indirect immunofluorescence or immunogold staining. Novel light and electron microscopical double and triple staining method employing primary antibodies from the same species. Histochemistry $83: 47-$ 56. CrossRef Medline

Wang H, Zylka MJ (2009) Mrgprd-expressing polymodal nociceptive neurons innervate most known classes of substantia gelatinosa neurons. J Neurosci 29:13202-13209. CrossRef Medline

Yang K, Kumamoto E, Furue H, Yoshimura M (1998) Capsaicin facilitates excitatory but not inhibitory synaptic transmission in substantia gelatinosa of the rat spinal cord. Neurosci Lett 255:135-138. CrossRef Medline

Zhou XF, Rush RA (1996) Endogenous brain-derived neurotrophic factor is anterogradely transported in primary sensory neurons. Neuroscience 74 945-953. CrossRef Medline 